\title{
Facile Synthesis of Stable and Highly Luminescent Methylammonium Lead Halide Nanocrystals for Efficient Light Emitting Devices
}

Yasser Hassan ${ }^{1}$, Olivia J. Ashton ${ }^{1}$, Jong Hyun Park ${ }^{4}$, Guangru Li ${ }^{2}$, Nobuya Sakai ${ }^{1}$, Bernard Wenger ${ }^{1}$, Amir-Abbas Haghighirad ${ }^{1,5}$, Nakita K. Noel ${ }^{1}$, Myoung Hoon Song ${ }^{4}$, Bo Ram Lee*2, 3 , Richard Friend*2 and Henry J. Snaith*1

${ }^{1}$ Clarendon Laboratory, Department of Physics, University of Oxford, Parks Road, Oxford OX1 3PU, UK

${ }^{2}$ Cavendish Laboratory, University of Cambridge, J J Thomson Avenue, Cambridge CB3 0HE, UK

${ }^{3}$ Department of Physics, Pukyong National University, 45 Yongso-ro, Nam-Gu, Busan 48513, Republic of Korea.

${ }^{4}$ School of Materials Science Engineering and KIST-UNIST Ulsan Center for Convergent Materials/Low Dimensional Carbon Center/Perovtronics Research Center, Ulsan National Institute of Science and Technology (UNIST), UNISTgil 50, Ulsan, 44919, Republic of Korea.

${ }^{5}$ Institute for Solid State Physics, Karlsruhe Institute of Technology, 76021, Karlsruhe, Germany

\begin{abstract}
Metal halide perovskites are promising candidates for use in light emitting diodes (LEDs), due to their potential for colour tuneable and high luminescence efficiency. While recent advances in perovskite-based light emitting diodes have resulted in external quantum efficiencies exceeding $12.4 \%$ for the green emitters, and infrared emitters based on 3D/2D mixed dimensional perovskites have exceeded $20 \%$, the external quantum efficiencies of the red and blue emitters still lag behind.-A critical issue to date is creating highly emissive and stable perovskite emitters with the desirable emission band gap to achieve full-colour displays and white LEDs. Herein, we report the preparation and characterization of a highly luminescent and stable suspension of cubic-shaped methylammonium lead triiodide $\mathrm{CH}_{3} \mathrm{NH}_{3} \mathrm{PbI}_{3}$ perovskite nanocrystals, where we synthesise the nanocrystals via a ligand-assisted re-precipitation technique, using an acetonitrile/methylamine compound solvent system to solvate the ions, and toluene as the anti-solvent to induce crystallisation. Through tuning the ratio of the ligands, the ligand to toluene ratio, and the temperature of the toluene, we obtain a solution of $\mathrm{CH}_{3} \mathrm{NH}_{3} \mathrm{PbI}_{3}$ nanocrystals with a photoluminescence quantum yield exceeding 93\%, and tuneable emission between $660 \mathrm{~nm}$ and
\end{abstract}


$705 \mathrm{~nm}$. We also achieved red emission at $635 \mathrm{~nm}$ by blending the nanocrystals with bromide salt and obtained perovskite-based light emitting diodes with maximum electroluminescent external quantum efficiency of $2.75 \%$.

\section{INTRODUCTION}

Over a relatively short period of time, incredible advances have been made in the development of metal halide perovskite-based thin films, bringing them to the forefront of emerging optoelectronic materials. ${ }^{1-6}$ Central to the impressive performance of perovskite-based optoelectronics devices, are their excellent luminescence properties, indicative of the low degree of non-radiative recombination which occurs within a well-fabricated perovskite film..$^{5,7-13}$ The emissive nature of these materials has already been exploited in the fabrication of efficient green ${ }^{14-15}$ and infrared ${ }^{12}$, ${ }^{16}$ LEDs, displaying real potential for the use of perovskites in solid-state lighting and display applications. ${ }^{17}$ In comparison to conventional organic and inorganic quantum dot emitters, perovskites have a unique combination of optical and electronic properties. ${ }^{18}$ In addition to exhibiting intense and narrow-band luminescence, the band gap can be tuned by both size control, and composition. ${ }^{7-13,19-21}$ In fact, tailoring the composition rather than the size, the emission position is likely to broaden the processing window in comparison to inorganic quantum dots, whereby the latter requires a very narrow size distribution to achieve high colour purity. In addition, perovskites can be fabricated using low-temperature processing techniques which should lead to more scalable fabrication. ${ }^{22}$ Most importantly, perovskites nanocrystals (NCs) exhibit exceptionally bright luminescence and have competitively high colour purity. ${ }^{7,}{ }^{19}$ However, in spite of this, the performance of perovskite-based light emitting diodes (PeLEDs) emitting in the visible region of the spectrum, is still modest in comparison to that of organic LEDs (OLEDs). ${ }^{23}$

In comparison to "bulk" polycrystalline thin films, colloidal perovskite NCs with small sizes 
provide a potential platform to increase exciton binding energy, and partially confine the electron and hole pairs (excitons) rather than formation of free carriers. ${ }^{18}$ This increases the competition between radiative (band to band) and non-radiative (trap assisted) recombination, and thus increases the radiative recombination at low excitations, which should lead to improved LED performance. ${ }^{18,21,24-25}$

To date, synthesis of highly emissive perovskite NCs has been achieved using two main approaches; the hot injection technique, or the room-temperature ligand-assisted re-precipitation (LARP) technique. ${ }^{26-27}$ Typically, in the LARP technique, the perovskite precursor salts are dissolved in a highly polar solvent (e.g. N,N-dimethylformamide (DMF), dimethyl sulfoxide (DMSO), and $\gamma$-butyrolactone (GBL)), and then injected into a non-polar solvent (e.g. toluene, hexane or octadecene (ODE)) containing long-chain capping ligands to produce luminescent, colloidal $\mathrm{NCs}$ such as that of $\mathrm{CH}_{3} \mathrm{NH}_{3} \mathrm{PbBr}_{3}$ with high photoluminescence quantum yield (PLQY). ${ }^{26}$ A critical challenge for the LARP methodology, is the potential entrapment of the highly coordinating solvents used in the synthesis. In particular the fast degradation of $\mathrm{CH} 3 \mathrm{NH}_{3} \mathrm{PbI}_{3}$ typically observed in solution, is thought to be due to the residual coordinated solvents (DMF and DMSO) on the surface of the crystals. ${ }^{28}$ Acetonitrile is less strongly coordinating polar aprotic solvent which may therefore be a useful "host" for nanocrystal synthesis. However, lead halide salts are only sparingly soluble in acetonitrile. Recently, Noel et al. have demonstrated that a compound solvent of methylamine dissolved in acetonitrile works as a very good solvent for metal halide salts. ${ }^{29}$ This therefore may be an appropriate solvent system in order to dissolve the perovskite precursor salts, while not introducing highly coordinating and complexing solvents. Although long chain amines are regularly added to assist synthesis in the LARP methodology, they strongly impact the crystal growth and crystal dimensions, and the 
precise composition and concentration of for instance oleylamine and oleic acid, strongly impact the final PLQY of the as synthesised nanocrystals. ${ }^{30}$ Therefore, relying upon the long chain amine to both solubilise the lead halide salts and control crystallisation may introduce a compromise upon required concentration. ${ }^{28}$ Whereas, adding a separately controllable concentration of methylamine, may decouple the solubilisation task from fine tuning of the nanocrystals synthesis via ligand chemistry.

While there have been significant advancements in the quality of the green-emitting $\mathrm{CH}_{3} \mathrm{NH}_{3} \mathrm{PbBr}_{3}$ $(>95 \% \text { PLQY })^{30-33}$ and $\mathrm{CsPbBr}_{3}\left(>90 \%\right.$ PLQY), ${ }^{27}$ synthesizing iodoplumbate NCs with a stable, red luminescence remains a challenge. ${ }^{28,30,34-37}$ To the best of our knowledge, previous studies showed that a maximum PLQY of only $46 \%$ has been achieved for $\mathrm{CH}_{3} \mathrm{NH}_{3} \mathrm{PbI}_{3} \mathrm{NCs}$ emitting at $730 \mathrm{~nm},{ }^{28} 38-40$ while the cesium analogues can reach close to unity efficiency at $690 \mathrm{~nm}$ emission wavelength. ${ }^{27,36-37}$ The red channel for displays is centred on $630 \mathrm{~nm}$ emission peak wavelength (Rec. 2020), and achieving stable and efficient emission at this wavelength is a key target for present research. ${ }^{41}$ The highest reported electroluminescent external quantum efficiency (ELEQE) for perovskite LEDs emitting in the "red region" of the visible spectrum are $6.2 \%$ efficiency for an LED incorporating a 2D layered perovskite emitting at $680 \mathrm{~nm}^{42-44}$, a very recent report of 12.2\% EL-EQE for an LED incorporating $\mathrm{CsPbX}_{3} \mathrm{NCs}$, emitting at $653 \mathrm{~nm}$, and 5\% efficiency for a mixed butylammonium, cesium and methylammonium lead mixed halide perovskite thinfilm emitting at $650 \mathrm{~nm} .{ }^{24,} 45-46$ When comparing these results, it is important to consider the photopic luminosity function, which describes the responsivity of the human eye to colour. With respect to the peak of the luminosity function at $555 \mathrm{~nm}$, the photopic luminosity function is 0.265 , $0.107,0.092$ and 0.017 at $630,650,653$ and $680 \mathrm{~nm}$ respectively. Therefore, assuming equal current density running through an LED, the perceived brightness of a $6.2 \%$ efficient LED at 680 
$\mathrm{nm}$ and a $12.2 \%$ efficient LED at $653 \mathrm{~nm}$, and a $5 \%$ efficient LED at $650 \mathrm{~nm}$, are only equivalent to a $0.40 \%$, a $4.24 \%$ and a $2.02 \%$ efficient $630 \mathrm{~nm}$ emitting LED, respectively.

Since the first investigations into perovskite $\mathrm{NCs}^{47}$, the effort on inorganic $\mathrm{CsPbX}_{3} \mathrm{NCs},{ }^{27},{ }^{30}$ has significantly swamped the effort on "hybrid" $\mathrm{NCs}^{34}$, such as the archetypical, $\mathrm{MAPbX}_{3}$, primarily due to the fact that it has proven much easier to synthesise highly emissive inorganic perovskite $\mathrm{NCs}^{48}$, coupled with the fact that the methylammonium based polycrystalline perovskite films have a lower thermal stability than Cs based perovskites. However, for iodine rich compositions of $\mathrm{CsPbX}_{3}$ perovskites, which are required for red emission, there remains a persistent phase instability ${ }^{37,48-49}$ Even though metastability has been achieved, eventual transition into the yellow non-perovskite orthorhombic phase occurs. ${ }^{36,50-51}$ Therefore, until a successful method to stabilise the "all-inorganic" cesium based perovskites emerges, it remains likely that a route to highly efficient and stable organic-inorganic perovskites with red channel emission is required.

Here, we demonstrate a facile synthetic approach for the preparation and characterization of highquality colloidal perovskite $\mathrm{CH}_{3} \mathrm{NH}_{3} \mathrm{PbI}_{3} \mathrm{NCs}$. We dissolve the perovskite precursor salts using the ACN/MA compound solvent, ${ }^{29}$ and synthesise the NCs using the LARP technique. By varying both the ligand ratio (oleic acid and oleylamine) and the temperature of the re-precipitation solvent, we are able to tune both the size and shape of the $\mathrm{CH}_{3} \mathrm{NH}_{3} \mathrm{PbI}_{3} \mathrm{NCs}$, achieving solutions, which are stable for over a year at ambient conditions, and PLQYs of over 90\%. We demonstrate the use of these NCs as active layers in LEDs achieving a maximum EL-EQE of 2\% at $740 \mathrm{~nm}$ emission peak. By tuning the halide composition, we synthesise $\mathrm{CH}_{3} \mathrm{NH}_{3} \mathrm{PbI}_{2} \mathrm{Br} \mathrm{NCs}$ which emit at $635 \mathrm{~nm}$, and achieved function perovskite LEDs with a maximum EL-EQE of $2.75 \%$ at $635 \mathrm{~nm}$.

\section{EXPERIMENTAL SECTION:}


All procedures were carried at ambient condition in the fume hood.

\section{Materials.}

All chemicals were used as received without further purification. Lead iodide $\left(\mathrm{PbI}_{2}\right)(99.99 \%)$ was purchased from TCI chemicals, methylammomium iodide (MAI) and methylammonium bromide (MABr) from Dyesol, oleic acid (99.0\%), oleylamine (70\%), methylamine (MA) solution (33\% in absolute ethanol), 1-Adamantanecarboxylic acid (ADAC) (99\%), dicarboxylic biphenyl-4,4'-dicarboxylic acid (97\%), butylamine ( $\geq 99 \%), 1$-Adamantylamine (97\%), 6-Amino2-naphthoic acid (90\%), and 3-Aminopropylphosphonic acid (98\%) were purchased from SigmaAldrich. All solvents such as toluene, acetonitrile, methyl acetate and ethyl acetate were anhydrous and were purchased from Sigma-Aldrich.

\section{Preparation of Lead Triiodide Perovskite Precursor.}

Lead iodide and methylammonium iodide was mixed in anhydrous acetonitrile. Typically, 2 mmol (0.922 $\mathrm{g}$ ) of $\mathrm{PbI}_{2}$ was mixed with $2 \mathrm{mmol}(0.318 \mathrm{~g})$ of MAI in $4 \mathrm{~mL}$ of anhydrous ACN which immediately form a black precipitate. This mixture was stirred to ensure complete reaction between MAI and $\mathrm{PbI}_{2}$. MA gas is then bubbled through this suspension, completely dissolving the perovskite to form a translucent pale yellow solution of perovskite-MAI complex. The formation of pure MA gas is described elsewhere. ${ }^{29}$ Briefly, a solution of MA in ethanol (Sigma Aldrich, $33 \mathrm{wt} \%$ ) was placed into a gas washing bottle which was kept in an ice bath to prevent water/ethanol from passing into the perovskite precursor. A carrier gas of $\mathrm{N}_{2}$ was then allowed to go through the solution using gas regulator, thus degassing the solution of MA. The bubbled MA gas was then passed through U-shape drying tube filled with a desiccant (Drierite and $\mathrm{CaO}$ ), before passing into the ACN mixture of perovskite precursors $(0.5 \mathrm{M}$ or as high as $1 \mathrm{M}$ concentration). Movie of dissolution of the perovskite precursor salts using the ACN/MA compound solvent is in 
Supporting Information.

\section{Preparation of Lead Mixed Halides Perovskite precursor.}

Similarly, to the aforementioned triiodide precursor, into $4 \mathrm{~mL}$ of anhydrous ACN $2 \mathrm{mmol}(0.922$ g) of $\mathrm{PbI}_{2}$ was mixed with $2 \mathrm{mmol}$ in total of a mixture of $(x \mathrm{MABr}+y \mathrm{MAI})$; i.e. modifying the bromide molar ratio in order to form the desired ratio of iodide to bromide in the NCs. For instance, forming the precursor for $\mathrm{CH}_{3} \mathrm{NH}_{3} \mathrm{PbBrI}_{2}:\left(2 \mathrm{mmol} \mathrm{PbI}_{2}+2 \mathrm{mmol} \mathrm{MABr}\right.$ were mixed in $4 \mathrm{~mL}$ anhydrous ACN before bubbling MA). Doping with bromides leads to formation of dark green precipitate in the ACN. This suspension undergoes afterwards to the MA bubbling process (see previous section).

\section{Synthesis of Lead Triiodide Perovskite NCs:}

Perovskite NCs were synthesized according to the previously reported LARP technique. In a typical synthesis, $5 \mathrm{~mL}$ of anhydrous toluene were mixed with $1 \mathrm{~mL}$ of oleic acid and $0.2 \mathrm{~mL}$ of oleylamine at controlled temperature (room temperature-60 ${ }^{\circ} \mathrm{C}$ ). Two hundreds microliters $(200 \mu \mathrm{L})$ of ACN/MA perovskite precursor solution was swiftly injected into the toluene/ligand mixture under vigorous stirring where the perovskite NCs immediately formed in seconds. The NCs were left stirring for ( 30 second -2 minutes) at the desired temperature for full growth of the desired NCs size. The solution of perovskite NCs was then moved to centrifuge tubes and centrifuged at $5000 \mathrm{rpm}$ for 5 minutes to remove aggregates and large particles. The resulted red supernatant colloidal solution was filtered using a PTFE syringe filter (Whatman, $0.2 \mu \mathrm{m}$ ) and stored for further characterizations.

\section{Synthesis of $\mathrm{CH}_{3} \mathrm{NH}_{3} \mathrm{PbI}_{2} \mathrm{Br}$ Perovskite NCs for Red Emission Region:}

Toluene $(5 \mathrm{~mL})$, oleic acid $(2 \mathrm{~mL})$, and oleylamine $(0.2 \mathrm{~mL})$ were mixed in a vial and heated on 
hotplate at $60{ }^{\circ} \mathrm{C}$. Subsequently, the perovskite precursor from the ACN/MA solution (0.2-0.4 mL) is swiftly injected into the hot toluene/ligand mixture. The reaction mixture was stirred for 2 minutes before being cooled down in an ice-water bath for another 2 minutes. We notice in case of mixed halides that excess of oleic acid is needed to initiate the NCs nucleation. The collected supernatant from this batch stored in a vial for washing process.

\section{Washing Process:}

For device fabrication and morphological characterizations, the NCs went through a washing process. Briefly, the perovskite NCs were purified by iteratively precipitating the NCs using an anti-solvent comprised of ethyl acetate and methyl acetate in a 2:1 ratio. We found that using solely methyl acetate in the case of $\mathrm{CH}_{3} \mathrm{NH}_{3} \mathrm{PbI}_{3} \mathrm{NCs}$ was too aggressive as an anti-solvent and led to the aggregation of the NCs. Typically, the toluene colloidal solution of NCs is added to the antisolvent in a ratio of $1: 3 \mathrm{v} / \mathrm{v}$. Then this mixture is centrifuged at $8000 \mathrm{rpm}$ for 20 minutes to precipitate the NCs. We discard the supernatant and re-dissolve the precipitate in toluene. This washing process is repeated twice before any further use of the NCs for characterizations or in device fabrication.

\section{Ligand Exchange and Treatment of $\mathrm{CH}_{3} \mathrm{NH}_{3} \mathrm{PbI}_{2} \mathrm{Br}$ Perovskite NCs}

For the ligand exchange, the NCs undergo two washing cycles with ethyl acetate/methyl acetate mixture as described above. Each NCs batch was dispersed in $2 \mathrm{~mL}$ of toluene after washing process. Six batches of washed NCs were combined making $12 \mathrm{~mL}$ of NCs $(40 \mathrm{mg} / \mathrm{mL})$ for stock. This solution was centrifuged at $5000 \mathrm{rpm}$ for 5 minutes to remove aggregates and large particles, and then divided equally into 2 vials: one was used as the control neat sample, while each of the other vial was treated by the ADAC ligand. Typically, into a $3 \mathrm{~mL}$ of NCs in toluene, a $2 \mathrm{mmol}$ of the ligand (ADAC were added) and stirred for overnight ( $\sim 12 \mathrm{hrs})$ at room temperature. The 
collected supernatant was filtered using a PTFE syringe filter (Whatman, $0.2 \mu \mathrm{m}$ ) and stored for further characterization and device work.

\section{Fabrication of $\mathrm{CH}_{3} \mathrm{NH}_{3} \mathrm{PbI}_{3}$ NCs-based PeLEDs (p-i-n):}

Indium tin oxide (ITO)-coated glass substrates were cleaned using sequential ultra-sonication in acetone and isopropanol for $10 \mathrm{~min}$ each. Then, poly (3,4-ethylenedioxythiophene): poly(styrenesulfonate) (PEDOT:PSS) (AI 4083, Clevios) was spin-coated at 5,000 rpm for $40 \mathrm{~s}$ and then annealed at $140{ }^{\circ} \mathrm{C}$ for 10 minutes. The $\mathrm{CH}_{3} \mathrm{NH}_{3} \mathrm{PbI}_{3} \mathrm{NCs}$ dispersion in toluene (20-40 $\mathrm{mg} / \mathrm{mL}$ ) was spin-coated onto PEDOT:PSS at 1,000 rpm for 30s in glovebox, then annealed at 50 ${ }^{\circ} \mathrm{C}$ for 2 minutes. SPB-02T (Merck) dispersed in chlorobenzene $(0.4$ wt. $\%)$ was spin-coated at 2,000 rpm for 45s. Finally, $\mathrm{LiF}(1 \mathrm{~nm})$ and silver $(100 \mathrm{~nm})$ were deposited successively by thermal evaporation.

\section{Fabrication of $\mathrm{CH}_{3} \mathrm{NH}_{3} \mathrm{PbI}_{3}$ NCs-based PeLEDs (n-i-p):}

A $7 \mathrm{mg} / \mathrm{ml}$ dispersion of $\mathrm{ZnO} \mathrm{NCs}$ in ethanol was spin-coated onto an ITO-coated glass substrate at $1500 \mathrm{rpm}$ for $30 \mathrm{~s}$, followed by annealing at $100^{\circ} \mathrm{C}$ for $10 \mathrm{~min}$ in a nitrogen-filled glovebox to give a $15 \mathrm{~nm}$ film. $\mathrm{CH}_{3} \mathrm{NH}_{3} \mathrm{PbI}_{3}$ Perovskite NCs dispersion in toluene was spin-coated at 1000$2000 \mathrm{rpm}$ for $20 \mathrm{~s}$ in air. The films were allowed to dry in air for $\sim 10 \mathrm{~min}$, and were transferred into an atomic layer deposition (ALD) chamber for crosslinking treatment. The crosslinking was carried out following literature. ${ }^{9}$ Following the crosslinking step, a solution of TFB in toluene (20 $\mathrm{mg} / \mathrm{mL}$ ) was spin-coated on top of the perovskite NCs at $2000 \mathrm{rpm}$ for $30 \mathrm{~s}$ in the glovebox to give a $60 \mathrm{~nm}$ thin film. $\mathrm{MoO}_{3}(5 \mathrm{~nm})$ and $\mathrm{Ag}(80 \mathrm{~nm})$ metal layers were deposited by thermal evaporation in a vacuum of $<5 \times 10^{-6}$ mbar. The devices were encapsulated by UV-epoxy.

\section{Fabrication of $\mathrm{CH}_{3} \mathrm{NH}_{3} \mathrm{PbI}_{2} \mathrm{Br}$ NCs-based PeLEDs:}


A PEDOT:PSS (AI 4083, Clevios) dispersion was spin-coated onto a cleaned ITO and annealed at $140^{\circ} \mathrm{C}$ for $10 \mathrm{~min}$. The hole transporting layer was fabricated by spin-coating Poly[N,N'-bis(4butylphenyl)-N,N'-bisphenylbenzidine] (Poly-TPD, OSM) chlorobenzene solution (12 mg mL-1) at $4000 \mathrm{rpm}$ for $40 \mathrm{~s}$. The $\mathrm{CH}_{3} \mathrm{NH}_{3} \mathrm{PbI}_{2} \mathrm{Br}$ perovskite $\mathrm{NCs}$ dispersed in toluene was spin-casted onto the substrate at $2000 \mathrm{rpm}$ for $40 \mathrm{~s}$ and annealed at $90^{\circ} \mathrm{C}$ for $5 \mathrm{~min}$. The electron transporting layer were fabricated by depositing $50 \mathrm{~nm}$ of 2,2',2"-(1,3,5-Benzinetriyl)-tris(1-phenyl-1-Hbenzimidazole) (TPBi, Ossila) using thermal evaporation system. Electrode were fabricated by depositing $1 \mathrm{~nm}$, in thickness, of $\mathrm{LiF}$ and $100 \mathrm{~nm}$ of Al using a thermal evaporation system.

\section{Characterization}

TEM, HRTEM and EDX. Size distributions and energy-dispersive X-ray spectra of the lead halide perovskite NCs on copper grid were determined by transmission electron microscopy using a JEOL JEM-2100 TEM with a LaB6 filament operating at $200 \mathrm{kV}$ for both low-magnification (TEM) and high-resolution (HRTEM) images.

$\boldsymbol{U V}$-vis Absorption spectra were recorded using a commercial Varian Cary 60 in a cuvette with a path length of $1 \mathrm{~cm}$.

Steady-state PL measurement was carried out with a spectrofluorometer (Fluorolog, Horiba JobinYvon), with a $450 \mathrm{~W}$ Xenon lamp excitation source and a photomultiplier tube detector. The excitation wavelength was $550 \mathrm{~nm}$ for $\mathrm{CH}_{3} \mathrm{NH}_{3} \mathrm{PbI}_{3} \mathrm{NCs}$, and was $450 \mathrm{~nm}$ for $\mathrm{CH}_{3} \mathrm{NH}_{3} \mathrm{PbI}_{2} \mathrm{Br}$ NCs.

Time-resolved PL measurement was obtained with Fluorescence Lifetime Spectrometer (Fluo Time 300, PicoQuant FmbH). The $\mathrm{CH}_{3} \mathrm{NH}_{3} \mathrm{PbI}_{3} \mathrm{NCs}$ in $1 \mathrm{~cm}$ cuvette were excited using a 505.5 nm laser. 
Powder X-ray diffraction (PXRD) patterns for phase purity were recorded on a Panalytical X'pert powder diffractometer (equipped with $\mathrm{Cu}-\mathrm{K} \alpha 1$ anode $\mathrm{X}$-ray source, and radiation; $\lambda=154.05$ pm; at room temperature ). Samples were rotated during data collection. All the samples were prepared for dried nanoparticle powder.

\section{Characterisation of $\mathrm{CH}_{3} \mathrm{NH}_{3} \mathrm{PbI}_{3} \mathrm{PeLEDs}$.}

Current versus voltage $(J-V)$ characteristics were measured using a Keithley 2400 Source Measure Unit. The photon flux emitted during the scan was measured simultaneously using a calibrated silicon photodiode centered over the light-emitting pixel, and the electroluminescent external quantum efficiency (EL-EQE) was calculated assuming a Lambertian emission profile. Luminance in $\mathrm{cd} \mathrm{m}^{-2}$ was calculated based on the emission spectrum of the LED, weighted against the standard luminosity function and on the known spectral response of the silicon photodiode. The electroluminescence spectra were measured using an optical fiber connected to a calibrated Ocean Optics USB 2000+ spectrometer. The emissive area of the device was $4.5 \mathrm{~mm}^{2}$. The devices were encapsulated before testing.

\section{Characterisation of $\mathrm{CH}_{3} \mathrm{NH}_{3} \mathrm{PbI}{ }_{2} \mathrm{Br}$ PeLEDs.}

For PeLEDs, J-V-L characteristics and device performances were measured using a Konica Minolta spectroradiometer (CS-2000) with Keithley 2400 source meter. The emissive area of the device was $13.5 \mathrm{~mm}^{2}$. The devices were encapsulated before testing.

\section{RESULTS AND DISCUSSION}

For our NCs synthesis we use the ACN saturated with MA as a medium for solvation of methylammonium lead halide perovskite precursor salts. ${ }^{29,} 52$ Then, we synthesize the NCs via a ligand-assisted re-precipitation (LARP) technique, by injecting the perovskite precursor from the ACN/MA solution into toluene as the anti-solvent, to induce crystallization. Briefly, we mix 
2 mmol of both lead iodide $\left(\mathrm{PbI}_{2}\right)$ and methylammonium iodide (MAI) with $\mathrm{ACN}$ forming a black dispersion of $\mathrm{CH}_{3} \mathrm{NH}_{3} \mathrm{PbI}_{3}$ perovskite, which is dissolved into the perovskite precursors solution (clear pale-yellow solution) upon bubbling dry MA gas into the ACN. Movie of dissolution of the perovskite precursor salts using the ACN/MA compound solvent is in Supporting Information.

We then swiftly inject the $\mathrm{CH}_{3} \mathrm{NH}_{3} \mathrm{PbI}_{3}$ precursor solution into anhydrous toluene (nucleation solvent) containing oleic acid and oleylamine as ligands, to trigger the crystallization of the NCs, while we maintain the reaction temperature at certain temperature (room temperature to $60{ }^{\circ} \mathrm{C}$ ). The ligands bind to the surface of the NCs, controlling their overall size and shape and preventing aggregation as well as passivating electronic trap states. ${ }^{26,53}$ We illustrate a schematic summary of the experimental procedure in (Figure 1) (See Experimental Methods for full details). During the formation of the NCs we maintain vigorous stirring and note that by varying the length of the growth period (from a few seconds ( 30 seconds) up to 2 minutes), we can modify the size of the NCs (Figure S1). We note that mixing the perovskite salts with the organic ligands before injecting them into toluene leads to the formation of a different material emitting at shorter wavelengths $(\leq$ $600 \mathrm{~nm}$ ) with PLQY of $30 \%$, which is consistent with the formation of a two-dimensional (2D) layered perovskite ${ }^{39}$, (Figure S2). Thus, to obtain the $3 \mathrm{D} \mathrm{CH}_{3} \mathrm{NH}_{3} \mathrm{PbI}_{3} \mathrm{NCs}$, we add the organic ligands into the toluene (re-precipitation solution). We purified the NCs by iteratively precipitating the NCs using an anti-solvent comprised of ethyl acetate and methyl acetate in a 2:1 ratio, followed by re-dispersion in toluene. We found that using solely methyl acetate as the anti-solvent was too aggressive and led to the aggregation of the $\mathrm{CH}_{3} \mathrm{NH}_{3} \mathrm{PbI}_{3} \mathrm{NCs}$. 

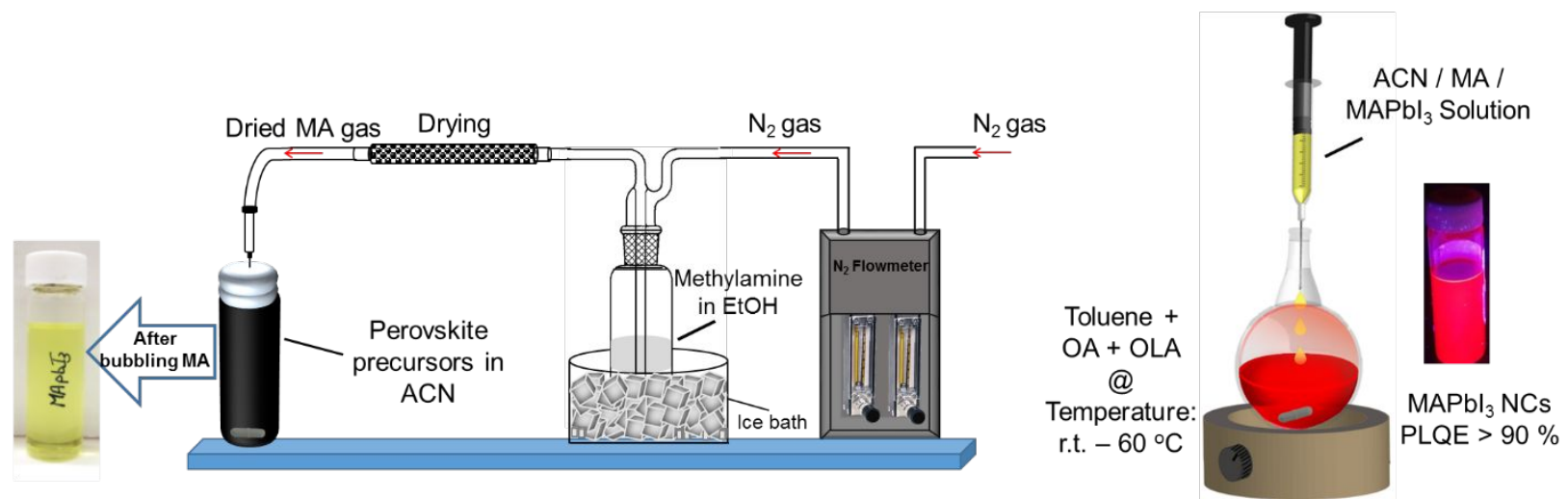

Figure 1: (A) Schematic illustration of the apparatus used for dissolving the perovskite precursor in the ACN solvent saturated by MA. (B) Schematic illustration of the synthesis of NCs by LARP technique. Movie of dissolution of the perovskite precursor salts using the ACN/MA compound solvent is in Supporting Information.

In order to assess if any Lewis complexes have formed in the perovskite precursor solution, we use Fourier-transform infrared spectroscopy (FTIR) for $\mathrm{CH}_{3} \mathrm{NH}_{3} \mathrm{PbI}_{3}$ perovskite salt precursors in ACN/MA and in DMF for comparison. Infrared transition energies are sensitive to both chemical composition and structural environment, which therefore present chemical evidence for complex formation. In (Figure 2), we show the FTIR spectrum for the ACN/MA solution, and compare this to the standard DMF solution. The vibrations at 1680 and 1090 are assigned to $\mathrm{C}=\mathrm{O}$ stretching vibration in DMF. As we show in (Figure 2b), $\mathrm{C}=\mathrm{O}$ peaks are broadened and downshifted relative to the original positions of the DMF solvent FTIR reference ${ }^{54}$, which we attribute to DMF coordination with the $\mathrm{PbI}_{2}$ in the perovskite precursor. However, wavenumbers between 900-1050 and from 1250-1575, assigned the $\mathrm{CH}_{3} \mathrm{NH}_{3}{ }^{+}$and $\mathrm{CH}_{3} \mathrm{NH}_{3} \mathrm{PbI}_{3},{ }^{55-56}$ are predominant with strong absorption in case of ACN precursor but not in the DMF precursor. These results are consistent with negligible solvent- $\mathrm{PbI}_{2}$ complex formation when we employ the ACN/MA solvent system, in contrast to when we employ the DMF solvent. 
(a)

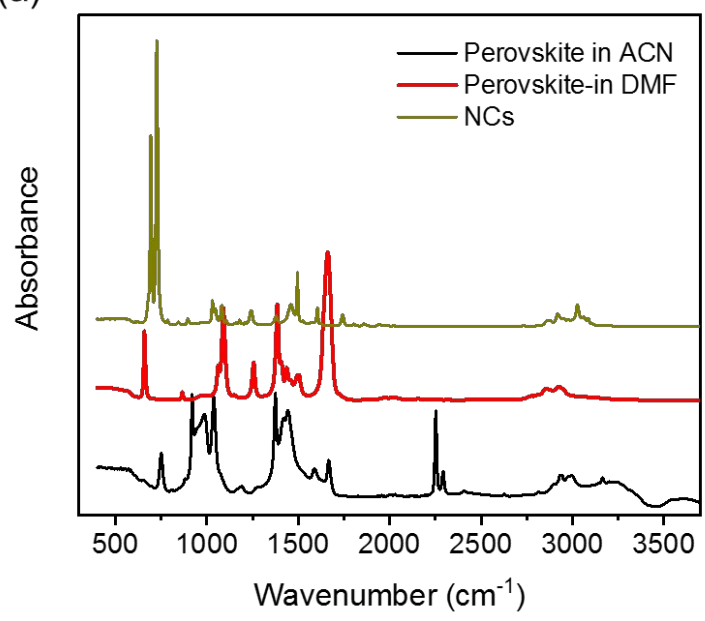

(b)

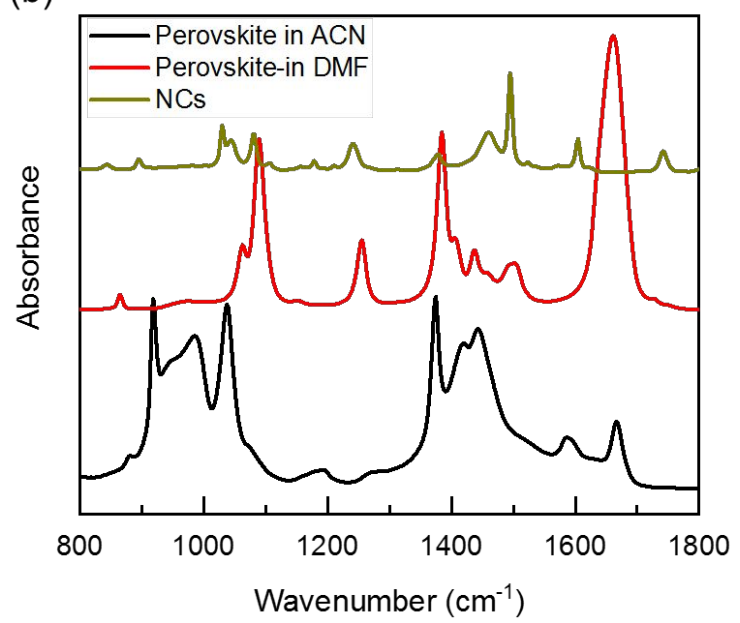

Figure 2: Fourier-transform infrared spectroscopy (FTIR) for $\mathrm{CH}_{3} \mathrm{NH}_{3} \mathrm{PbI}_{3}$ perovskite salt precursor in ACN/MA compound solvent, the precursor in DMF, and compared to $\mathrm{CH}_{3} \mathrm{NH}_{3} \mathrm{PbI}_{3}$ $\mathrm{NCs}$ in toluene.

We investigate the effects of ligand concentration, temperature, and reaction time. Firstly, we optimize the ratio of oleic acid to oleylamine in toluene to give the most luminescent NCs. We find that we obtain the highest PLQY when using a 5:1 v/v ratio of oleic acid to oleylamine. In addition, we observe that increasing the oleylamine part in the mixture prevents the precipitation of the NCs, while the excess amount of oleic acid in the solution is essential for initiating the crystallization process and the formation of the NCs. As such, for all other investigations discussed here, we have kept the ratio of oleic acid to oleylamine to perovskite precursor $5: 1: 1 \mathrm{v} / \mathrm{v} / \mathrm{v}$.

We examine morphological and structural properties of the synthesized NCs using a variety of techniques including powder X-ray diffraction (PXRD), transmission electron microscopy (TEM), and high-resolution TEM (HRTEM).

TEM studies, which we show in (Figure 3a), reveal the formation of $\mathrm{CH}_{3} \mathrm{NH}_{3} \mathrm{PbI}_{3}$ nanoparticles of cubic-shape with a diameter of roughly 10-15 nm. From HRTEM (Figure 3a; inset), we observe well-developed lattice fringes, and the fast Fourier transformation (FFT) reveals the (110), and (002) planes with an interplanar spacing of $0.44 \mathrm{~nm}$, and $0.63 \mathrm{~nm}$, respectively, identified for the 
tetragonal phase, which are in agreement with the XRD results (see Figure $3 b$ ). These TEM and HRTEM measurements confirm the high crystallinity of the $\mathrm{CH}_{3} \mathrm{NH}_{3} \mathrm{PbI}_{3} \mathrm{NCs}$ sample.

We investigate the role of the reaction temperature on the structural and optical properties of the NCs in the range of room temperature to $60{ }^{\circ} \mathrm{C}$. We find that while the synthesis temperature does not affect the PLQY of the resulting NCs, it does affect the NCs shape. At $60{ }^{\circ} \mathrm{C}$, cubic shape NCs are produced, however at lower temperatures, we obtain a mixture of dot-like and spherical shapes (Figure S3). The reaction time was varied from 30 seconds to 2 minutes. The reaction time was found to have minimal effect on the size of the crystals (Figure S1). Incidentally, we observe that our washed NCs remain stable in a toluene solvent without degradation for over a year, as judged by solution clarity and PLQY, at ambient conditions, (Figure S4). 
(a)

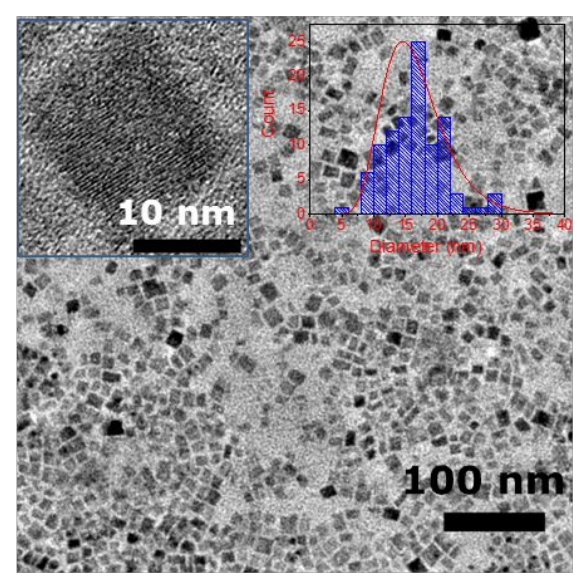

(c)

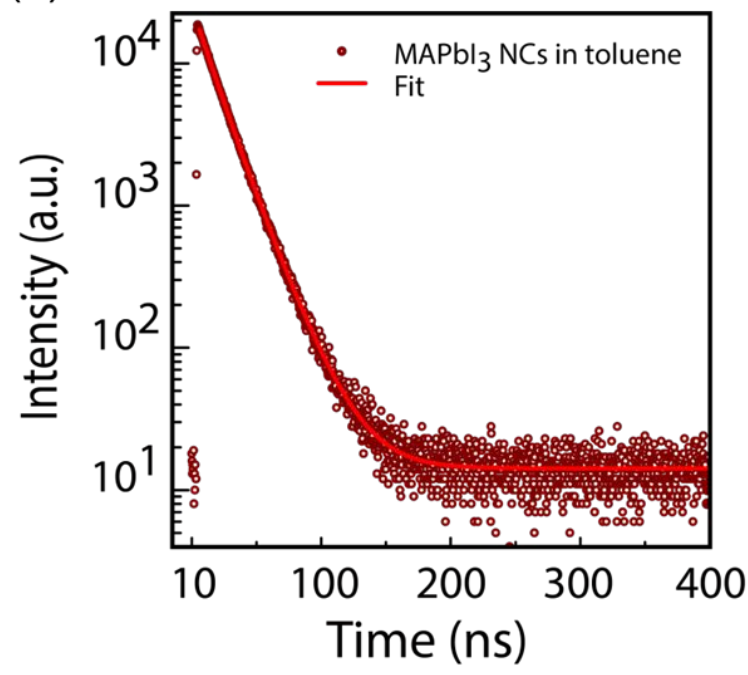

(b)

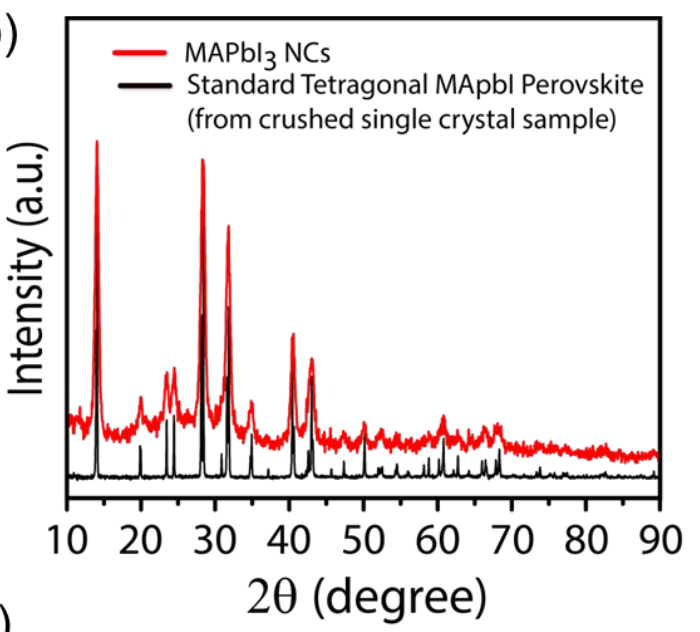

(d)

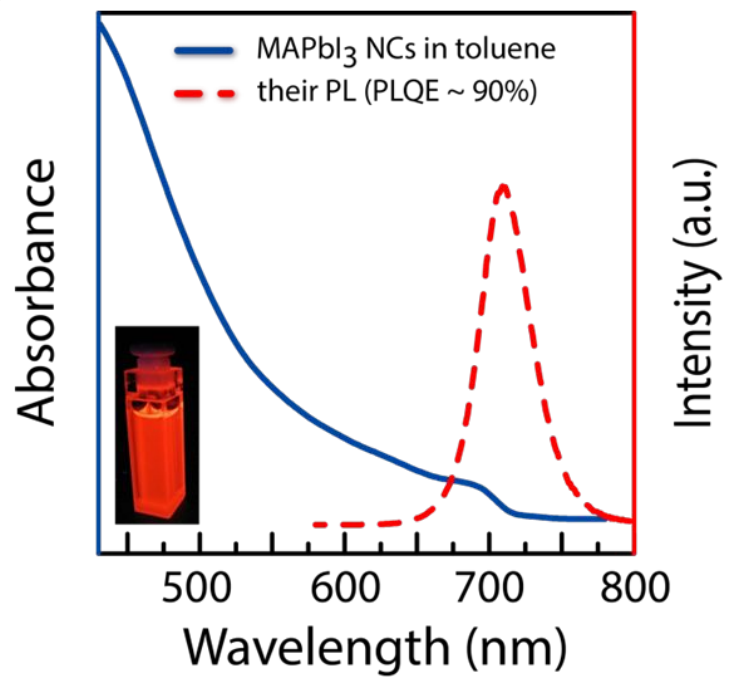

Figure 3: Structural and optical properties and characterization of methylammonium lead triiodide perovskite NCs. (a) Low-magnification transmission electron micrograph (TEM) analysis for $\mathrm{CH}_{3} \mathrm{NH}_{3} \mathrm{PbI}_{3} \mathrm{NCs}$ synthesized from perovskite precursor dissolved in ACN/MA compound solvent at $60{ }^{\circ} \mathrm{C}$ with the size of (average diameter of $\sim 15 \mathrm{~nm}$ ). Inset: High-resolution electron microscopy (HRTEM), and particle size distribution including the lognormal curve. (b) Powder X-ray diffractogram of our synthesized $\mathrm{CH}_{3} \mathrm{NH}_{3} \mathrm{PbI}_{3} \mathrm{NCs}$ (red line) compared to the standard tetragonal phase of $\mathrm{CH}_{3} \mathrm{NH}_{3} \mathrm{PbI}_{3}$ perovskite (black line). The XRD results for $\mathrm{CH}_{3} \mathrm{NH}_{3} \mathrm{PbI}_{3}$ powder, which was deposited on a glass substrate at room temperature from a concentrated colloidal NCs solution washed by mixture of methyl acetate and ethyl acetate. Perovskite reflection peaks are assigned to the tetragonal perovskite crystal lattice. The plot

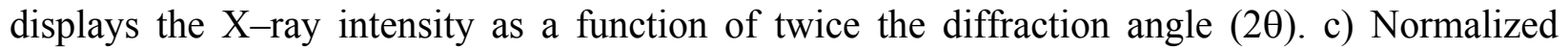
absorption and steady-state photoluminescence (PL) spectra of $\mathrm{CH}_{3} \mathrm{NH}_{3} \mathrm{PbI}_{3} \mathrm{NCs}$ in toluene where the NCs size has $15 \mathrm{~nm}$ diameter and clearly exhibiting a quantum confinement effect. d) Timeresolved PL decay and fitting curve of a typical $\mathrm{CH}_{3} \mathrm{NH}_{3} \mathrm{PbI}_{3} \mathrm{NCs}$ in toluene.

In (Figure 3b) we present the X-ray powder diffraction (PXRD) patterns of as-synthesized $\mathrm{CH}_{3} \mathrm{NH}_{3} \mathrm{PbI}_{3} \mathrm{NCs}$. Strong reflection peaks at $14.05^{\circ}, 19.97^{\circ}, 24.4^{\circ}, 28.8^{\circ}, 31.79^{\circ}, 40.42^{\circ}$ and $43.43^{\circ}$, 
corresponding to the (110), (200), (202), (220), (114), (321) and (402) planes, respectively, indicate high crystallinity of a typical diffraction pattern indexed as $\mathrm{CH}_{3} \mathrm{NH}_{3} \mathrm{PbI}_{3}$ tetragonal phase (space group I4/mcm) $)^{38,50,57-58}$, compared to reference peak (black line) obtained from a crushed, tetragonal single crystal of $\mathrm{CH}_{3} \mathrm{NH}_{3} \mathrm{PbI}_{3} .{ }^{59}$ The broadening of the PXRD peaks, with respect to those of the single crystal, is due to the small size of the NCs. ${ }^{26-27}$

We further studied the optical properties of our NCs using UV-vis spectroscopy, steady-state photoluminescence (PL) measurements, PLQY and time-resolved PL. In (Figure 3c), we show the room temperature absorption (red) and steady-state PL emission (black) spectra corresponding to $\mathrm{CH}_{3} \mathrm{NH}_{3} \mathrm{PbI}_{3} \mathrm{NCs}$ dispersed in toluene. We used the same solution to measure the time-resolved PL decay, (Figure 3d). The UV-Vis absorption and the PL spectra of these NCs exhibit an absorption onset, at $\sim 698 \mathrm{~nm}$, which is blue-shifted compared to the corresponding bulk films of $\mathrm{CH}_{3} \mathrm{NH}_{3} \mathrm{PbI}_{3}{ }^{60-61}$ Moreover, we noticed that by changing the particle size we can tune the absorption edge (and the steady-state PL emission) from $\sim 698-715 \mathrm{~nm}$ for $\sim 10-25 \mathrm{~nm}$ sized particles to $665-670 \mathrm{~nm}$ for 4-5 nm sized particles (Figure S5). The steady-state PL spectrum of the resultant NCs shows narrow emission peak with a FWHM of $\sim 40-50 \mathrm{~nm}$. The resultant neat $\mathrm{CH}_{3} \mathrm{NH}_{3} \mathrm{PbI}_{3} \mathrm{NCs}$ emit with a PLQY over $90 \%$.

We measure the PL lifetime of the NCs to study the carrier recombination kinetics. In (Figure 3d) we show a typical time-resolved $\mathrm{PL}$ decay for $\mathrm{CH}_{3} \mathrm{NH}_{3} \mathrm{PbI}_{3} \mathrm{NCs}$ with a PL emission peak position $(\sim 704 \mathrm{~nm})$, where the excitation wavelength is $505 \mathrm{~nm}$ and the excitation intensity is $21.0 \mathrm{~nJ} / \mathrm{cm}^{2}$. We fitted the early time decay curve using mono-exponential function, resulting in a lifetime of 14 ns. This short PL life time compared to the bulk $\mathrm{CH}_{3} \mathrm{NH}_{3} \mathrm{PbI}_{3}$ perovskite is in agreement with the previous reports of small NCs and related to the relative confinement of the electron hole-pair, which accelerates the bimolecular radiative recombination. ${ }^{26,28,62}$ 
Based on the above high-quality perovskite NCs, we sought to investigate their application in LEDs. We tested both the p-i-n (Figure 4) and n-i-p (Figure S6) perovskites LED (PeLED) configurations for the $\mathrm{CH}_{3} \mathrm{NH}_{3} \mathrm{PbI}_{3} \mathrm{NCs}$. In (Figure 4a) we show a schematic illustration of our p-i-n PeLED, which has a structure of ITO/ PEDOT:PSS/ $\mathrm{CH}_{3} \mathrm{NH}_{3} \mathrm{PbI}_{3} \mathrm{NCs} / \mathrm{SPB}-02 \mathrm{~T} / \mathrm{LiF} / \mathrm{Ag}$ (refer to the Experimental Section for more details).

(a)

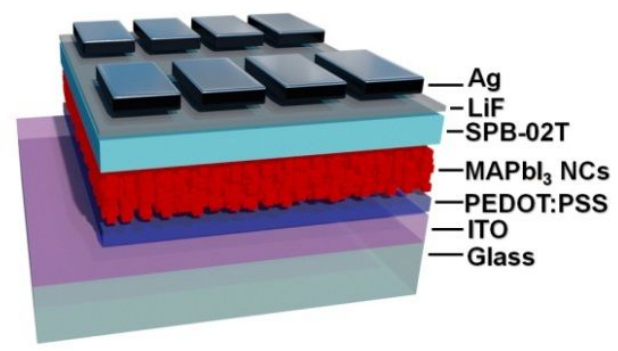

(c)

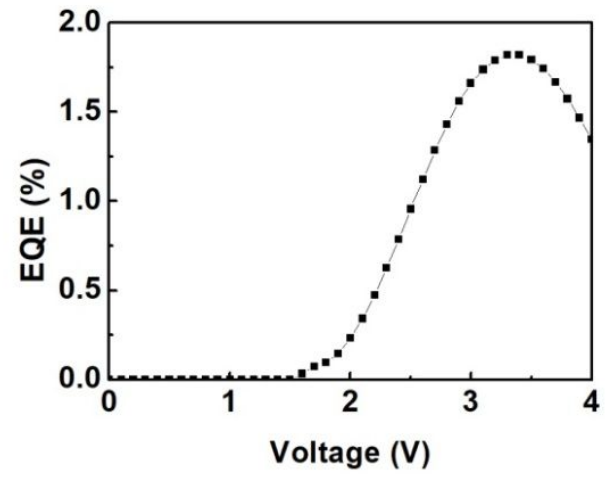

(b)

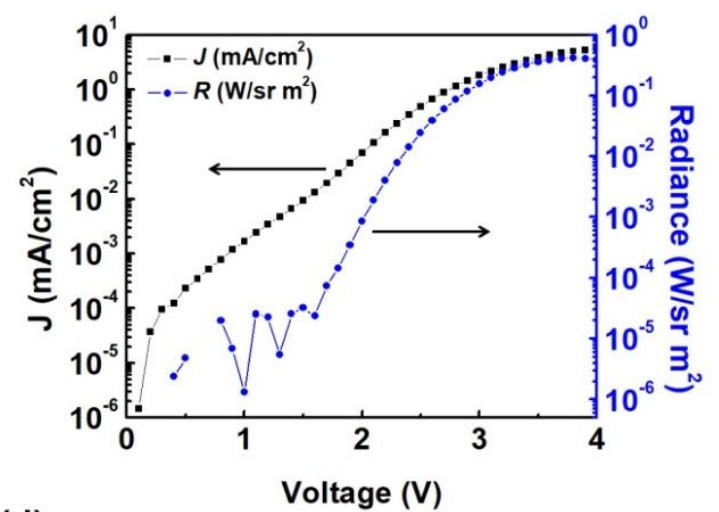

(d)

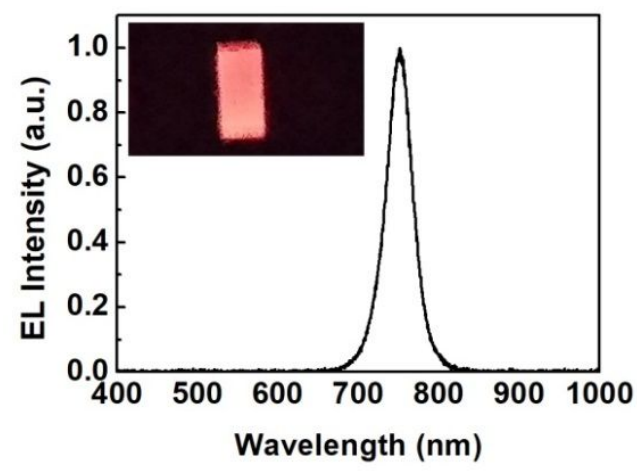

Figure 4: Device characterization of $\mathrm{CH}_{3} \mathrm{NH}_{3} \mathrm{PbI}_{3}$ NCs-based PeLEDs: (a) Schematic illustrations of PeLEDs devices and (b-d) device performances of optimized PeLEDs including (b) current density versus voltage (J-V) characteristics and radiance versus applied voltage (R-V), (c) EL-EQE versus applied voltage (EQE-V) and (d) electroluminescence (EL) spectra of PeLEDs; inset: photographs of EL emission.

In (Figure 4b) we show the current density $(\mathrm{J})$ and radiance $(\mathrm{R})$ versus the applied voltage $(V)$, in (Figure 4c) we show the EL-EQE versus the voltage and in (Figure 4d) we show the electroluminescence (EL) spectra from a PeLEDs. We measure a maximum EL-EQE of 1.82\% for our p-i-n PeLED, which is similar to the value of $1.9 \%$ which we achieved with an $n-i-p$ structure 
(which we show in (Figure S6)). Table S1 summarizes the data of the PeLEDs-based on these two configurations of $\mathrm{CH}_{3} \mathrm{NH}_{3} \mathrm{PbI}_{3}$ NCs-based PeLEDs. The EL peak of the $\mathrm{CH}_{3} \mathrm{NH}_{3} \mathrm{PbI}_{3} \mathrm{NCs}$ emissive layer exhibits a slightly redshifted wavelength (EL $\sim 740 \mathrm{~nm}$ ) in comparison to the steadystate PL spectra of NCs solution (PL 705 nm; $15 \mathrm{~nm}$ in size). This shift has been explained previously due to the dielectric dispersion that leads to NCs proximity in films. ${ }^{63}$

The main motivation of our work is to achieve efficient luminescence in the red region, where for displays the emission peak should be at $\sim 630 \mathrm{~nm} .{ }^{41}$ Firstly, we attempted to tune the size of the $\mathrm{CH}_{3} \mathrm{NH}_{3} \mathrm{PbI}_{3} \mathrm{NCs}$ to smaller sizes $(4 \mathrm{~nm})$, but the largest blue shift which we achieved on steadystate PL results in an emission maximum at $670 \mathrm{~nm}$, (Figure S5). Therefore, we tuned the halide composition with increasing percentage of bromide. Among different compositions of mixed halides, we found that the $\mathrm{PL}$ of fresh solutions and films of the $\mathrm{CH}_{3} \mathrm{NH}_{3} \mathrm{PbI}_{2} \mathrm{Br}$ emit at the desired red region, at 630-635 $\mathrm{nm}$ (Figure S7). Hence, we focus on this composition for the following section.

In a typical synthesis of $\mathrm{CH}_{3} \mathrm{NH}_{3} \mathrm{PbI}_{2} \mathrm{Br} \mathrm{NCs}$, we mixed toluene (5mL), oleic acid $(2 \mathrm{~mL})$, and oleylamine $(0.2 \mathrm{~mL})$ at $60{ }^{\circ} \mathrm{C}$ before swiftly injecting the $\mathrm{CH}_{3} \mathrm{NH}_{3} \mathrm{PbI}_{2} \mathrm{Br}$ perovskite precursor from ACN/MA compound solvent solution $(0.2 \mathrm{~mL})$. In (Figure S8a), we show TEM images of $\mathrm{CH}_{3} \mathrm{NH}_{3} \mathrm{PbI}_{2} \mathrm{Br} \mathrm{NCs}$, which reveals a cubic shape, while from XRD of the same NCs, we confirm a tetragonal structure, (Figure S8b). We therefore conclude that the incorporation of $\mathrm{Br}^{-}$in the composition of the NCs does not change the shape and structure (in comparison with the $\mathrm{CH}_{3} \mathrm{NH}_{3} \mathrm{PbI}_{3} \mathrm{NCs}$ ) yet it widens the bandgap of the crystal due to a shrinking of the lattice, influencing the octahedral tilting, as well as changing the electronic configuration. ${ }^{64}$ We measured the PLQY of the $\mathrm{CH}_{3} \mathrm{NH}_{3} \mathrm{PbI}_{2} \mathrm{Br} \mathrm{NCs}$ in solution to be in the range of $40-60 \%$, with an emission peak at $635 \mathrm{~nm}$. In order to remove the unreacted precursors, as is standard procedure, we rinsed 
and re-precipitated the NCs twice in methyl acetate. However, after this rinsing process the PLQY drops down to $\sim 20 \%$. It is possible to recover the higher PLQY values by adding more oleic acid to the washed NCs, indicating that the drop in PLQY after rinsing is due to loss of ligand from the surface. Unfortunately however, the insulating fatty acid (oleic acid) is detrimental to the charge conduction in the subsequently formed films.

As a means of enhancing the PLQY of the washed mixed halide NCs, without having to add more large insulating ligands, we explore post synthesis ligand exchange and test their performance in PeLEDs. We investigate ligands containing the following groups: carboxylic acids (e.g. 1adamantanecarboxylic acid (ADAC)), dicarboxylic acids (e.g. Biphenyl-4,4'-dicarboxylic acid), amines (butylamine, 1-Adamantylamine), and amino acids (e.g. 6-Amino-2-naphthoic acid, or 3Aminopropylphosphonic acid). Typically, we undertook ligand exchange of the $\mathrm{CH}_{3} \mathrm{NH}_{3} \mathrm{PbI}_{2} \mathrm{Br}$ NCs by adding the ligand powder directly into the toluene solution of the previously washed NCs (concentration: $2 \mathrm{mmol}$ of the ligands and $40 \mathrm{mg}$ of the NCs in toluene). We observe increased PLQY with addition of acids and amino acids, while addition of amines tends to dissolve the perovskite crystals (i.e. red solutions turn yellow). This is in agreement with previous surface studies of similar NCs, where alkylamines act as ligands if they are protonated into their ammonium salts in the presence of excess acid, while amines on their own dissolve the NCs. ${ }^{65-67}$ Amongst the range of ligands explored, we found that ADAC and 3-Aminopropylphosphonic acid added to the toluene solution at 18 and $50 \mathrm{mg} / \mathrm{ml}$ respectively, enhanced the PLQY of washed $\mathrm{CH}_{3} \mathrm{NH}_{3} \mathrm{PbI}_{2} \mathrm{Br} \mathrm{NCs}$ from $20-25 \%$ to nearly $60-85 \%$ in solution, at $635 \mathrm{~nm}$ peak emission. Notably, ADAC is the most soluble in toluene, of the ligands we assessed. We assume that this enables a higher concentration of ligand to interact with the surface of the NCs, (re)passivating surface defects. The $\mathrm{CH}_{3} \mathrm{NH}_{3} \mathrm{PbI}_{2} \mathrm{Br} \mathrm{NCs}$ solid film exhibits steady-state PL emission at $635 \mathrm{~nm}$ 


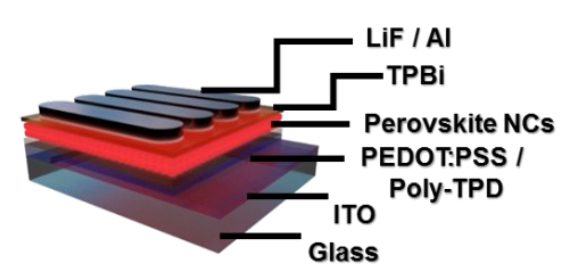

(b)

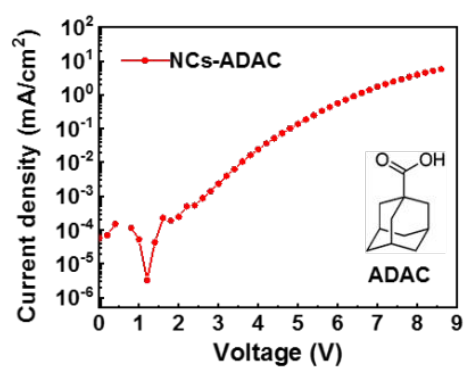

(e)

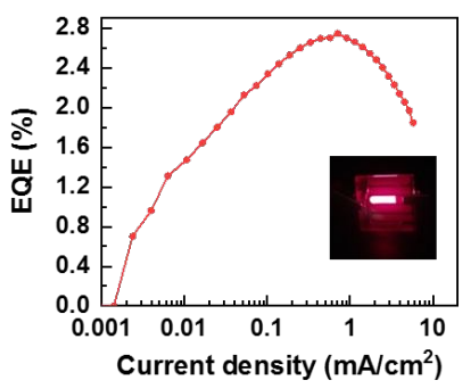

(a)

(d)

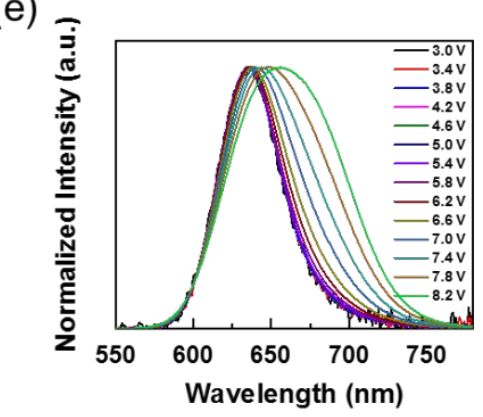

and PLQY of 30\%, with a FWHM of $43 \mathrm{~nm}$, which we show in (Figure S9).

We further examine the interaction of ADAC with the surface of the NCs using attenuated total reflection-FTIR (ATR-FTIR). By comparing films containing $\mathrm{CH}_{3} \mathrm{NH}_{3} \mathrm{PbI}_{2} \mathrm{Br}$ NCs capped with $\mathrm{ADAC}$, to films containing neat NCs, we provide evidence for direct interaction of the ligands with the $\mathrm{CH}_{3} \mathrm{NH}_{3} \mathrm{PbI}_{2} \mathrm{Br}$ NCs. The IR results are discussed in detail in the Supporting Information and in (Figure S10). ${ }^{66,68}$ Moreover, we treated $\mathrm{CH}_{3} \mathrm{NH}_{3} \mathrm{PbI}_{2} \mathrm{Br}$ bulk film with ADAC and measure their PLQY before and after the treatment. We find that the treatment with ADAC enhanced the PLQY of the $\mathrm{CH}_{3} \mathrm{NH}_{3} \mathrm{PbI}_{2} \mathrm{Br}$ bulk films from $0.3 \%$ to $3.7 \%$, indicating that ADAC also improves the quality of the films.

(c)

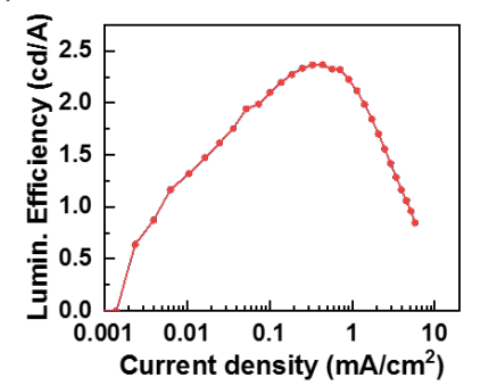

(f)

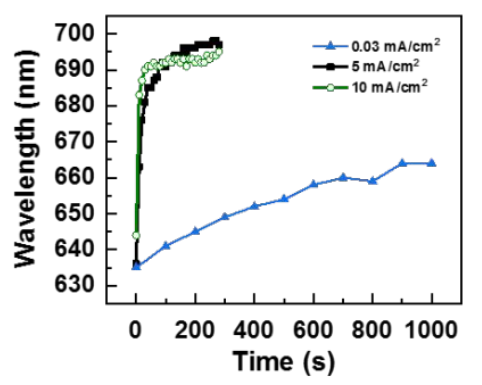

Figure 5: Device characterization of mixed halides $\mathrm{CH}_{3} \mathrm{NH}_{3} \mathrm{PbI} \mathrm{I}_{2} \mathrm{Br}$ NCs: (a) Schematic illustrations of PeLEDs based on NCs-capped with 1-adamantanecarboxylic acid (ADAC), showing the device architecture: ITO/PEDOT:PSS (40 nm)/poly-TPD (30 nm)/ $\mathrm{CH}_{3} \mathrm{NH}_{3} \mathrm{PbI}_{2} \mathrm{Br}$ NCs $(20 \mathrm{~nm}) / \mathrm{TPBi}(40 \mathrm{~nm}) / \mathrm{LiF}(1 \mathrm{~nm}) / \mathrm{Al}(100 \mathrm{~nm})$. (b-d) device performances of optimized PeLEDs including: (b) current density versus voltage (J-V) characteristics, (c) Luminous Efficiency (L) versus current density (J-L), and (d) EL-EQE of these devices versus current density (J-EQE); inset: photographs of EL red emission. (e) electroluminescence (EL) spectra peak energy of PeLEDs as a function of driving voltage of the device based NCs-capped with ADAC. (f) EL maximum position versus the time at low current density of $0.03 \mathrm{~mA} / \mathrm{cm}^{2}$, and higher current 
densities of 5 and $10 \mathrm{~mA} / \mathrm{cm}^{2}$.

To examine the utility of these red emitting mixed halide $\mathrm{NCs}\left(\mathrm{CH}_{3} \mathrm{NH}_{3} \mathrm{PbI}{ }_{2} \mathrm{Br}\right)$, we fabricated and tested PeLEDs comparing the neat and ADAC ligand exchanged NCs. For these PeLEDs, we used the p-i-n configuration of ITO/PEDOT:PSS/poly-TPD/CH${ }_{3} \mathrm{NH}_{3} \mathrm{PbI}_{2} \mathrm{Br}$ NCs/TPBi/LiF/Al, a schematic of which we show in (Figure 5a). In (Figure 5b, c, and d), we show the efficiency of the PeLEDs of the device based on $\mathrm{CH}_{3} \mathrm{NH}_{3} \mathrm{PbI}_{2} \mathrm{Br}$ NCs-capped with ADAC as well as the current density and luminous efficiency versus applied voltage characteristics. In (Figure 5e), we show the EL emission maximum position as a function of voltage during measurement. The PeLEDs results based on $\mathrm{CH}_{3} \mathrm{NH}_{3} \mathrm{PbI}{ }_{2} \mathrm{Br}$ neat NCs without ligand exchange are presented in (Figure S11). Table S2 summarize the data of the PeLEDs-based on these mixed halides. Initially, the EL peak matches well with the PL peak position of the solid-films (i.e. $635 \mathrm{~nm}$; (Figure S9), and we obtain bright red luminescence at $\sim 635 \mathrm{~nm}$ with EL-EQE of $2.75 \%$. Considering the photopic response, the efficiency of this LED corresponds to an EL-EQE value of $2.25 \%$, emitting at $630 \mathrm{~nm}$. This value is therefore competitive with other "red" emitting perovskite LEDs based on 2D layered and Csbased perovskite emitter layers. ${ }^{42-46}$, and represents the most efficient methylammonium lead halide based LEDs at this wavelength.

We note however, that after increasing the voltage above $6.2 \mathrm{~V}$, the emission spectrum red-shifts, which is consistent with the previously observed halide segregation. ${ }^{24,}{ }^{69-71}$ Our observation is consistent with iodine rich domains forming during operation of the PeLEDs..$^{24,70}$ In order to test the band gap stability of PeLEDs-based on NC-capped with ADAC, we measured the emission spectrum as a function of time, for a range of fixed current densities. In (Figure 5f), we show the EL emission maximum position versus the time at low current density of $0.03 \mathrm{~mA} / \mathrm{cm}^{2}$, as well as at higher current densities of 5 , and $10 \mathrm{~mA} / \mathrm{cm}^{2}$. For the lowest current density, the emission peak 
shifts from 635 to $639 \mathrm{~nm}$ over the first 100 seconds, and reaches $\sim 664 \mathrm{~nm}$ position at longer time (i.e. 1000 seconds). (Figure S12) shows the EL-EQE and the Luminance (L) of these PeLEDsbased on NC-capped with ADAC versus this low current density of $0.03 \mathrm{~mA} / \mathrm{cm}^{2}$ over time. However, when we drive higher, more practically relevant current densities through the PeLEDs, the EL emission peak shifts from 635 to $\sim 695 \mathrm{~nm}$, reaching this position faster at higher current density. We do note, although this EL peak has red shifted from $635 \mathrm{~nm}$, this EL peak is considerably blue shifted with respect to the EL from $\mathrm{CH}_{3} \mathrm{NH}_{3} \mathrm{PbI}_{3} \mathrm{NCs}$ LEDs (i.e. $\sim 740 \mathrm{~nm}$; Figure $4 d$ ). Therefore, despite having demonstrated that mixing the halides is a very effective means of obtaining the desired emission wavelength, we demonstrate that halide segregation appears to be a critical issue in obtaining stable red $(630 \mathrm{~nm})$ electroluminescence. This is therefore a key area which will require a significant focussed research effort to resolve. Beyond color stability, absolute stability of EL efficiency is clearly a critical factor for enabling commercially useful perovskite LEDs. Today's commercial OLEDs have lifetimes in the range of 100,000 hours. ${ }^{72}$ The best reported "lifetimes" for perovskite LEDs are only tens of hours (46 hours) to sustain $50 \%$ of their original EL efficiency. ${ }^{73}$ In the early stages of research, all technologies are unstable, and OLEDs are a perfect example of this. ${ }^{74-75}$ However, long term stability is clearly a very important future direction for perovskite LED research.

\section{CONCLUSIONS}

In summary, we have developed a reproducible and facile synthetic approach for the preparation and characterization of high-quality, colloidally stable, cubic-shaped $\mathrm{CH}_{3} \mathrm{NH}_{3} \mathrm{PbI}_{3} \mathrm{NCs}$ and their mixed halide analogues. We have demonstrated that dissolving the perovskite salts in the acetonitrile saturated by methylamine compound solvent, enables rapid and uniform nucleation and growth of the NCs at low temperatures $\left(60{ }^{\circ} \mathrm{C}\right)$. Through tuning the ratio of the ligands, the 
ligand to toluene ratio, and the temperature of the toluene, we are able to obtain a solution of $\mathrm{CH}_{3} \mathrm{NH}_{3} \mathrm{PbI}_{3} \mathrm{NCs}$ with a PL quantum yield exceeding $90 \%$. Importantly, we synthesized the NCs in open air, without need for glovebox or inert conditions. Furthermore, we have demonstrated the synthesis of mixed halide NCs with the desired red emission at 630-635 nm, and through appropriate ligand selection achieved a maximum PLQY of $85 \%$ in solution, and $30 \%$ in solid film. We incorporated these NCs into LEDs, resulting in a maximum EL-EQE of $\sim 2 \%$ for $\mathrm{CH}_{3} \mathrm{NH}_{3} \mathrm{PbI}_{3} \mathrm{NCs}$-based devices and 2.75\% for the $\mathrm{CH}_{3} \mathrm{NH}_{3} \mathrm{PbI}_{2} \mathrm{Br}$ NCs-based devices emitting at $635 \mathrm{~nm}$. These LED performances are the highest EL-EQE reported so far for the methylammonium cation-based lead iodide perovskite NCs. However, we have highlighted a critical key challenge of halide segregation for mixed halide perovskite NCs used in LEDs, which requires further effort in order to resolve. The synthetic approach we have presented, represents a simple and effective route for synthesizing hybrid perovskite NCs for advancing the future light emission applications based on these materials.

\author{
ASSOCIATED CONTENT \\ Supporting Information \\ The Supporting Information is available free of charge on the \\ ACS Publications website at DOI: \\ Description of experimental methods of the synthesis of the NCs and the fabrication of the PeLEDs. \\ Further characterization of the materials and devices studied. (PDF) \\ Movie of dissolution of the perovskite precursor salts using the ACN/MA compound solvent. (Avi)
}

\title{
AUTHOR INFORMATION
}

Corresponding Authors

*henry.snaith@physics.ox.ac.uk

*brlee@pknu.ac.kr 


\begin{abstract}
Author Contributions
All authors have given approval to the final version of the manuscript.

O. J. Ashton and and J. H. Park contributed equally.
\end{abstract}

\title{
ORCID
}

Yasser Hassan: 0000-0003-3887-1752

Olivia J. Ashton: 0000-0002-0886-2110

Jong Hyun Park: 0000-0002-0581-0809

Nakita K. Noel: 0000-0002-8570-479X

Guangru Li: 0000-0001-7300-5679

Bernard Wenger: 0000-0001-9026-7064

Amir-Abbas Haghighirad: 0000-0003-4723-4966

Nobuya Sakai: 0000-0003-2142-6564

Myoung Hoon Song: 0000-0002-8106-7332

Bo Ram Lee: 0000-0002-4670-6717

Richard H. Friend: 0000-0001-6565-6308

Henry J. Snaith: 0000-0001-8511-790X

\section{Notes}

The authors declare no competing financial interests.

\section{ACKNOWLEDGMENT}

This work was partially funded by the Engineering and Physical Sciences Research Council (EPSRC) UK through Grants EP/M005143/1, and EP/M015254/2. B.W. thanks the European Commission for Marie Skłodowska-Curie actions individual fellowship (REA grant number: 706552-APPEL). B.R.L. was supported by the National Research Foundation of Korea (NRF2018R1C1B6005778) and the Pukyong National University Research Fund (CD20171504). Authors are thankful to Dr. Sai Bai for supplying the $\mathrm{ZnO}$ nanoparticles used in the device work. Y.H is thankful to Dr. Ashley Marshall, and Dr. Victor Burlakov for their useful discussions on the manuscript, and thankful for Dr. Matthew Klug and Dr. Tawfeek Ismael for helping drawing (Figure 1b).

\section{References}

1. Kojima, A.; Teshima, K.; Shirai, Y.; Miyasaka, T., Organometal Halide Perovskites as Visible-Light Sensitizers for Photovoltaic Cells. Journal of the American Chemical Society 2009, 131 (17), 6050-6051.

2. Lee, M. M.; Teuscher, J.; Miyasaka, T.; Murakami, T. N.; Snaith, H. J., Efficient Hybrid Solar Cells Based on Meso-Superstructured Organometal Halide Perovskites. Science 2012, 338 (6107), 643-647. 
3. Kim, H.-S.; Lee, C.-R.; Im, J.-H.; Lee, K.-B.; Moehl, T.; Marchioro, A.; Moon, S.-J.; Humphry-Baker, R.; Yum, J.-H.; Moser, J. E.; Grätzel, M.; Park, N.-G., Lead lodide Perovskite Sensitized All-Solid-State Submicron Thin Film Mesoscopic Solar Cell with Efficiency Exceeding 9\%. Scientific Reports 2012, 2, 591.

4. Bush, K. A.; Palmstrom, A. F.; Yu, Z. J.; Boccard, M.; Cheacharoen, R.; Mailoa, J. P.; McMeekin, D. P.; Hoye, R. L. Z.; Bailie, C. D.; Leijtens, T.; Peters, I. M.; Minichetti, M. C.; Rolston, N.; Prasanna, R.; Sofia, S.; Harwood, D.; Ma, W.; Moghadam, F.; Snaith, H. J.; Buonassisi, T.; Holman, Z. C.; Bent, S. F.; McGehee, M. D., 23.6\%-efficient monolithic perovskite/silicon tandem solar cells with improved stability. Nature Energy 2017, 2, 17009.

5. $\quad$ Tan, Z.-K.; Moghaddam, R. S.; Lai, M. L.; Docampo, P.; Higler, R.; Deschler, F.; Price, M.; Sadhanala, A.; Pazos, L. M.; Credgington, D.; Hanusch, F.; Bein, T.; Snaith, H. J.; Friend, R. H., Bright light-emitting diodes based on organometal halide perovskite. Nature Nanotechnology 2014, 9, 687.

6. Deschler, F.; Price, M.; Pathak, S.; Klintberg, L. E.; Jarausch, D.-D.; Higler, R.; Hüttner, S.; Leijtens, T.; Stranks, S. D.; Snaith, H. J.; Atatüre, M.; Phillips, R. T.; Friend, R. H., High Photoluminescence Efficiency and Optically Pumped Lasing in Solution-Processed Mixed Halide Perovskite Semiconductors. The Journal of Physical Chemistry Letters 2014, 5 (8), 1421-1426. 7. Cho, H.; Jeong, S.-H.; Park, M.-H.; Kim, Y.-H.; Wolf, C.; Lee, C.-L.; Heo, J. H.; Sadhanala, A.; Myoung, N.; Yoo, S.; Im, S. H.; Friend, R. H.; Lee, T.-W., Overcoming the electroluminescence efficiency limitations of perovskite light-emitting diodes. Science 2015, 350 (6265), 1222-1225.

8. Yuan, M.; Quan, L. N.; Comin, R.; Walters, G.; Sabatini, R.; Voznyy, O.; Hoogland, S.; Zhao, Y.; Beauregard, E. M.; Kanjanaboos, P.; Lu, Z.; Kim, D. H.; Sargent, E. H., Perovskite energy funnels for efficient light-emitting diodes. Nat Nano 2016, 11 (10), 872-877.

9. Li, G.; Rivarola, F. W. R.; Davis, N. J. L. K.; Bai, S.; Jellicoe, T. C.; de la Peña, F.; Hou, S.; Ducati, C.; Gao, F.; Friend, R. H.; Greenham, N. C.; Tan, Z.-K., Highly Efficient Perovskite Nanocrystal Light-Emitting Diodes Enabled by a Universal Crosslinking Method. Advanced Materials 2016, 28 (18), 3528-3534.

10. Deng, W.; Xu, X.; Zhang, X.; Zhang, Y.; Jin, X.; Wang, L.; Lee, S.-T.; Jie, J., Organometal Halide Perovskite Quantum Dot Light-Emitting Diodes. Advanced Functional Materials 2016, 26 (26), 4797-4802.

11. Song, J.; Li, J.; Li, X.; Xu, L.; Dong, Y.; Zeng, H., Quantum Dot Light-Emitting Diodes Based on Inorganic Perovskite Cesium Lead Halides (CsPbX3). Advanced Materials 2015, 27 (44), 71627167.

12. Xiao, Z.; Kerner, R. A.; Zhao, L.; Tran, N. L.; Lee, K. M.; Koh, T.-W.; Scholes, G. D.; Rand, B. P., Efficient perovskite light-emitting diodes featuring nanometre-sized crystallites. Nature Photonics 2017, 11 (2), 108-115.

13. Zhang, L.; Yang, X.; Jiang, Q.; Wang, P.; Yin, Z.; Zhang, X.; Tan, H.; Yang, Y.; Wei, M.; Sutherland, B. R.; Sargent, E. H.; You, J., Ultra-bright and highly efficient inorganic based perovskite light-emitting diodes. Nature Communications 2017, 8, 15640.

14. Yang, X.; Zhang, X.; Deng, J.; Chu, Z.; Jiang, Q.; Meng, J.; Wang, P.; Zhang, L.; Yin, Z.; You, J., Efficient green light-emitting diodes based on quasi-two-dimensional composition and phase engineered perovskite with surface passivation. Nature Communications 2018, 9 (1), 570.

15. Cho, H.; Kim, J. S.; Wolf, C.; Kim, Y.-H.; Yun, H. J.; Jeong, S.-H.; Sadhanala, A.; Venugopalan, V.; Choi, J. W.; Lee, C.-L.; Friend, R. H.; Lee, T.-W., High-Efficiency Polycrystalline 
Perovskite Light-Emitting Diodes Based on Mixed Cations. ACS Nano 2018, 12 (3), 2883-2892. 16. Zou, W.; Li, R.; Zhang, S.; Liu, Y.; Wang, N.; Cao, Y.; Miao, Y.; Xu, M.; Guo, Q.; Di, D.; Zhang, L.; Yi, C.; Gao, F.; Friend, R. H.; Wang, J.; Huang, W., Minimising efficiency roll-off in highbrightness perovskite light-emitting diodes. Nature Communications 2018, 9 (1), 608.

17. Lozano, G., The Role of Metal Halide Perovskites in Next-Generation Lighting Devices. The Journal of Physical Chemistry Letters 2018, 3987-3997.

18. Kim, Y.-H.; Cho, H.; Lee, T.-W., Metal halide perovskite light emitters. Proceedings of the National Academy of Sciences 2016, 113 (42), 11694.

19. Tan, Z.-K.; Moghaddam, R. S.; Lai, M. L.; Docampo, P.; Higler, R.; Deschler, F.; Price, M.; Sadhanala, A.; Pazos, L. M.; Credgington, D.; Hanusch, F.; Bein, T.; Snaith, H. J.; Friend, R. H., Bright light-emitting diodes based on organometal halide perovskite. Nat Nano 2014, 9 (9), 687692.

20. Stranks, S. D.; Burlakov, V. M.; Leijtens, T.; Ball, J. M.; Goriely, A.; Snaith, H. J., Recombination Kinetics in Organic-Inorganic Perovskites: Excitons, Free Charge, and Subgap States. Physical Review Applied 2014, 2 (3), 034007.

21. K., K. N.; Dhritiman, G.; Dinesh, K., Recent Advances in Metal Halide-Based Perovskite Light-Emitting Diodes. Energy Technology 2017, 5 (10), 1734-1749.

22. Docampo, P.; Ball, J. M.; Darwich, M.; Eperon, G. E.; Snaith, H. J., Efficient organometal trihalide perovskite planar-heterojunction solar cells on flexible polymer substrates. Nature Communications 2013, 4, 2761.

23. Kumawat, N. K.; Gupta, D.; Kabra, D., Recent Advances in Metal Halide-Based Perovskite Light-Emitting Diodes. Energy Technology 2017, 5 (10), 1734-1749.

24. Xiao, Z.; Zhao, L.; Tran, N. L.; Lin, Y. L.; Silver, S. H.; Kerner, R. A.; Yao, N.; Kahn, A.; Scholes, G. D.; Rand, B. P., Mixed-Halide Perovskites with Stabilized Bandgaps. Nano Letters 2017, 17 (11), 6863-6869.

25. Si, J.; Liu, Y.; He, Z.; Du, H.; Du, K.; Chen, D.; Li, J.; Xu, M.; Tian, H.; He, H.; Di, D.; Lin, C.; Cheng, Y.; Wang, J.; Jin, Y., Efficient and High-Color-Purity Light-Emitting Diodes Based on In Situ Grown Films of CsPbX3 (X = Br, I) Nanoplates with Controlled Thicknesses. ACS Nano 2017, 11 (11), 11100-11107.

26. Zhang, F.; Zhong, H.; Chen, C.; Wu, X.-g.; Hu, X.; Huang, H.; Han, J.; Zou, B.; Dong, Y., Brightly Luminescent and Color-Tunable Colloidal $\mathrm{CH}_{3} \mathrm{NH}_{3} \mathrm{PbX}_{3}(\mathrm{X}=\mathrm{Br}, \mathrm{I}, \mathrm{Cl})$ Quantum Dots: Potential Alternatives for Display Technology. ACS Nano 2015.

27. Protesescu, L.; Yakunin, S.; Bodnarchuk, M. I.; Krieg, F.; Caputo, R.; Hendon, C. H.; Yang, R. X.; Walsh, A.; Kovalenko, M. V., Nanocrystals of Cesium Lead Halide Perovskites (CsPbX 3 , X = $\mathrm{Cl}, \mathrm{Br}$, and I): Novel Optoelectronic Materials Showing Bright Emission with Wide Color Gamut. Nano Letters 2015, 15 (6), 3692-3696.

28. Zhang, F.; Huang, S.; Wang, P.; Chen, X.; Zhao, S.; Dong, Y.; Zhong, H., Colloidal Synthesis of Air-Stable CH3NH3PbI3 Quantum Dots by Gaining Chemical Insight into the Solvent Effects. Chemistry of Materials 2017, 29 (8), 3793-3799.

29. Noel, N. K.; Habisreutinger, S. N.; Wenger, B.; Klug, M. T.; Horantner, M. T.; Johnston, M. B.; Nicholas, R. J.; Moore, D. T.; Snaith, H. J., A low viscosity, low boiling point, clean solvent system for the rapid crystallisation of highly specular perovskite films. Energy \& Environmental Science 2017, 10 (1), 145-152.

30. Gonzalez-Carrero, S.; Francés-Soriano, L.; González-Béjar, M.; Agouram, S.; Galian, R. E.; 
Pérez-Prieto, J., The Luminescence of $\mathrm{CH} 3 \mathrm{NH} 3 \mathrm{PbBr} 3$ Perovskite Nanoparticles Crests the Summit and Their Photostability under Wet Conditions is Enhanced. Small 2016, 12 (38), 52455250.

31. Gonzalez-Carrero, S.; Galian, R. E.; Perez-Prieto, J., Maximizing the emissive properties of $\mathrm{CH} 3 \mathrm{NH} 3 \mathrm{PbBr} 3$ perovskite nanoparticles. Journal of Materials Chemistry A 2015, 3 (17), 9187 9193.

32. Sun, H.; Yang, Z.; Wei, M.; Sun, W.; Li, X.; Ye, S.; Zhao, Y.; Tan, H.; Kynaston, E. L.; Schon, T. B.; Yan, H.; Lu, Z.-H.; Ozin, G. A.; Sargent, E. H.; Seferos, D. S., Chemically Addressable Perovskite Nanocrystals for Light-Emitting Applications. Advanced Materials 2017, 29 (34), 1701153.

33. Huang, H.; Susha, A. S.; Kershaw, S. V.; Hung, T. F.; Rogach, A. L., Control of Emission Color of High Quantum Yield CH3NH3PbBr3 Perovskite Quantum Dots by Precipitation Temperature. Advanced Science 2015, 2 (9), 1500194.

34. Pathak, S.; Sakai, N.; Wisnivesky Rocca Rivarola, F.; Stranks, S. D.; Liu, J.; Eperon, G. E.; Ducati, C.; Wojciechowski, K.; Griffiths, J. T.; Haghighirad, A. A.; Pellaroque, A.; Friend, R. H.; Snaith, H. J., Perovskite Crystals for Tunable White Light Emission. Chemistry of Materials 2015, 27 (23), 8066-8075.

35. Swarnkar, A.; Marshall, A. R.; Sanehira, E. M.; Chernomordik, B. D.; Moore, D. T.; Christians, J. A.; Chakrabarti, T.; Luther, J. M., Quantum dot-induced phase stabilization of alpha-CsPbl3 perovskite for high-efficiency photovoltaics. Science 2016, 354 (6308), 92-95. 36. Huang, H.; Bodnarchuk, M. I.; Kershaw, S. V.; Kovalenko, M. V.; Rogach, A. L., Lead Halide Perovskite Nanocrystals in the Research Spotlight: Stability and Defect Tolerance. ACS Energy Letters 2017, 2 (9), 2071-2083.

37. Protesescu, L.; Yakunin, S.; Kumar, S.; Bär, J.; Bertolotti, F.; Masciocchi, N.; Guagliardi, A.; Grotevent, M.; Shorubalko, I.; Bodnarchuk, M. I.; Shih, C.-J.; Kovalenko, M. V., Dismantling the "Red Wall" of Colloidal Perovskites: Highly Luminescent Formamidinium and FormamidiniumCesium Lead lodide Nanocrystals. ACS Nano 2017, 11 (3), 3119-3134.

38. Vybornyi, O.; Yakunin, S.; Kovalenko, M. V., Polar-solvent-free colloidal synthesis of highly luminescent alkylammonium lead halide perovskite nanocrystals. Nanoscale 2016, 8 (12), 6278-6283.

39. Hassan, Y.; Song, Y.; Pensack, R. D.; Abdelrahman, A. I.; Kobayashi, Y.; Winnik, M. A.; Scholes, G. D., Structure-Tuned Lead Halide Perovskite Nanocrystals. Advanced Materials 2016, $28(3), 566-573$.

40. Imran, M.; Caligiuri, V.; Wang, M.; Goldoni, L.; Prato, M.; Krahne, R.; De Trizio, L.; Manna, L., Benzoyl Halides as Alternative Precursors for the Colloidal Synthesis of Lead-Based Halide Perovskite Nanocrystals. Journal of the American Chemical Society 2018, 140 (7), 26562664.

41. Zhu, R.; Luo, Z.; Chen, H.; Dong, Y.; Wu, S.-T., Realizing Rec. 2020 color gamut with quantum dot displays. Opt. Express 2015, 23 (18), 23680-23693.

42. Tian, Y.; Zhou, C.; Worku, M.; Wang, X.; Ling, Y.; Gao, H.; Zhou, Y.; Miao, Y.; Guan, J.; Ma, B., Highly Efficient Spectrally Stable Red Perovskite Light-Emitting Diodes. Advanced Materials 2018, 30 (20), 1707093.

43. Chang, J.; Zhang, S.; Wang, N.; Sun, Y.; Wei, Y.; Li, R.; Yi, C.; Wang, J.; Huang, W., Enhanced Performance of Red Perovskite Light-Emitting Diodes through the Dimensional 
Tailoring of Perovskite Multiple Quantum Wells. The Journal of Physical Chemistry Letters 2018, 9 (4), 881-886.

44. Cao, Y.; Wang, N.; Tian, H.; Guo, J.; Wei, Y.; Chen, H.; Miao, Y.; Zou, W.; Pan, K.; He, Y.; Cao, H.; Ke, Y.; Xu, M.; Wang, Y.; Yang, M.; Du, K.; Fu, Z.; Kong, D.; Dai, D.; Jin, Y.; Li, G.; Li, H.; Peng, Q.; Wang, J.; Huang, W., Perovskite light-emitting diodes based on spontaneously formed submicrometre-scale structures. Nature 2018, 562 (7726), 249-253.

45. Zhang, X.; Sun, C.; Zhang, Y.; Wu, H.; Ji, C.; Chuai, Y.; Wang, P.; Wen, S.; Zhang, C.; Yu, W. W., Bright Perovskite Nanocrystal Films for Efficient Light-Emitting Devices. The Journal of Physical Chemistry Letters 2016, 7 (22), 4602-4610.

46. Chiba, T.; Hayashi, Y.; Ebe, H.; Hoshi, K.; Sato, J.; Sato, S.; Pu, Y.-J.; Ohisa, S.; Kido, J., Anion-exchange red perovskite quantum dots with ammonium iodine salts for highly efficient light-emitting devices. Nature Photonics 2018, 12 (11), 681-687.

47. Schmidt, L. C.; Pertegás, A.; González-Carrero, S.; Malinkiewicz, O.; Agouram, S.; Mínguez Espallargas, G.; Bolink, H. J.; Galian, R. E.; Pérez-Prieto, J., Nontemplate Synthesis of $\mathrm{CH} 3 \mathrm{NH} 3 \mathrm{PbBr} 3$ Perovskite Nanoparticles. Journal of the American Chemical Society 2014, 136 (3), 850-853.

48. Pan, J.; Shang, Y.; Yin, J.; De Bastiani, M.; Peng, W.; Dursun, I.; Sinatra, L.; El-Zohry, A. M.; Hedhili, M. N.; Emwas, A.-H.; Mohammed, O. F.; Ning, Z.; Bakr, O. M., Bidentate LigandPassivated CsPb|3 Perovskite Nanocrystals for Stable Near-Unity Photoluminescence Quantum Yield and Efficient Red Light-Emitting Diodes. Journal of the American Chemical Society 2018, 140 (2), 562-565.

49. Sutton, R. J.; Eperon, G. E.; Miranda, L.; Parrott, E. S.; Kamino, B. A.; Patel, J. B.; Hörantner, M. T.; Johnston, M. B.; Haghighirad, A. A.; Moore, D. T.; Snaith, H. J., BandgapTunable Cesium Lead Halide Perovskites with High Thermal Stability for Efficient Solar Cells. Advanced Energy Materials 2016, 6 (8), 1502458.

50. Kovalenko, M. V.; Protesescu, L.; Bodnarchuk, M. I., Properties and potential optoelectronic applications of lead halide perovskite nanocrystals. Science 2017, 358 (6364), 745-750.

51. Sutton, R. J.; Filip, M. R.; Haghighirad, A. A.; Sakai, N.; Wenger, B.; Giustino, F.; Snaith, H. J., Cubic or Orthorhombic? Revealing the Crystal Structure of Metastable Black-Phase CsPbl3 by Theory and Experiment. ACS Energy Letters 2018, 3 (8), 1787-1794.

52. Noel, N. K.; Wenger, B.; Habisreutinger, S. N.; Patel, J. B.; Crothers, T.; Wang, Z.; Nicholas, R. J.; Johnston, M. B.; Herz, L. M.; Snaith, H. J., Highly Crystalline Methylammonium Lead Tribromide Perovskite Films for Efficient Photovoltaic Devices. ACS Energy Letters 2018, 1233-1240.

53. Kim, Y.-H.; Wolf, C.; Kim, Y.-T.; Cho, H.; Kwon, W.; Do, S.; Sadhanala, A.; Park, C. G.; Rhee, S.-W.; Im, S. H.; Friend, R. H.; Lee, T.-W., Highly Efficient Light-Emitting Diodes of Colloidal Metal-Halide Perovskite Nanocrystals beyond Quantum Size. ACS Nano 2017, 11 (7), 65866593.

54. Yahui, L.; Zhenhao, Z.; Feng, L.; Xiaobing, C.; Xian, C.; Jinquan, W., In Situ Observation of Crystallization of Methylammonium Lead lodide Perovskite from Microdroplets. Small 2017, 13 (26), 1604125.

55. Glaser, T.; Müller, C.; Sendner, M.; Krekeler, C.; Semonin, O. E.; Hull, T. D.; Yaffe, O.; Owen, J. S.; Kowalsky, W.; Pucci, A.; Lovrinčić, R., Infrared Spectroscopic Study of Vibrational 
Modes in Methylammonium Lead Halide Perovskites. The Journal of Physical Chemistry Letters 2015, 6 (15), 2913-2918.

56. Patel, J. B.; Milot, R. L.; Wright, A. D.; Herz, L. M.; Johnston, M. B., Formation Dynamics of $\mathrm{CH} 3 \mathrm{NH} 3 \mathrm{~Pb} 33$ Perovskite Following Two-Step Layer Deposition. The Journal of Physical Chemistry Letters 2016, 7 (1), 96-102.

57. Stoumpos, C. C.; Malliakas, C. D.; Kanatzidis, M. G., Semiconducting Tin and Lead lodide Perovskites with Organic Cations: Phase Transitions, High Mobilities, and Near-Infrared Photoluminescent Properties. Inorganic Chemistry 2013, 52 (15), 9019-9038.

58. Shamsi, J.; Abdelhady, A. L.; Accornero, S.; Arciniegas, M.; Goldoni, L.; Kandada, A. R. S.; Petrozza, A.; Manna, L., N-Methylformamide as a Source of Methylammonium Ions in the Synthesis of Lead Halide Perovskite Nanocrystals and Bulk Crystals. ACS Energy Letters 2016, 1 (5), 1042-1048.

59. Nayak, P. K.; Moore, D. T.; Wenger, B.; Nayak, S.; Haghighirad, A. A.; Fineberg, A.; Noel, N. K.; Reid, O. G.; Rumbles, G.; Kukura, P.; Vincent, K. A.; Snaith, H. J., Mechanism for rapid growth of organic-inorganic halide perovskite crystals. Nature Communications 2016, 7, 13303. 60. Anaya, M.; Rubino, A.; Rojas, T. C.; Galisteo-López, J. F.; Calvo, M. E.; Míguez, H., Strong Quantum Confinement and Fast Photoemission Activation in CH3NH3Pbl3 Perovskite Nanocrystals Grown within Periodically Mesostructured Films. Advanced Optical Materials 2017, 5 (8), 1601087.

61. Malgras, V.; Tominaka, S.; Ryan, J. W.; Henzie, J.; Takei, T.; Ohara, K.; Yamauchi, Y., Observation of Quantum Confinement in Monodisperse Methylammonium Lead Halide Perovskite Nanocrystals Embedded in Mesoporous Silica. Journal of the American Chemical Society 2016, 138 (42), 13874-13881.

62. D'Innocenzo, V.; Srimath Kandada, A. R.; De Bastiani, M.; Gandini, M.; Petrozza, A., Tuning the Light Emission Properties by Band Gap Engineering in Hybrid Lead Halide Perovskite. Journal of the American Chemical Society 2014, 136 (51), 17730-17733.

63. Wood, V.; Panzer, M. J.; Caruge, J.-M.; Halpert, J. E.; Bawendi, M. G.; Bulović, V., AirStable Operation of Transparent, Colloidal Quantum Dot Based LEDs with a Unipolar Device Architecture. Nano Letters 2010, 10 (1), 24-29.

64. Jizhong, S.; Jianhai, L.; Xiaoming, L.; Leimeng, X.; Yuhui, D.; Haibo, Z., Quantum Dot Light-Emitting Diodes Based on Inorganic Perovskite Cesium Lead Halides (CsPbX3). Advanced Materials 2015, 27 (44), 7162-7167.

65. Almeida, G.; Goldoni, L.; Akkerman, Q.; Dang, Z.; Khan, A. H.; Marras, S.; Moreels, I.; Manna, L., Role of Acid-Base Equilibria in the Size, Shape, and Phase Control of Cesium Lead Bromide Nanocrystals. ACS Nano 2018, 12 (2), 1704-1711.

66. Almeida, G.; Ashton, O. J.; Goldoni, L.; Maggioni, D.; Petralanda, U.; Mishra, N.; Akkerman, Q. A.; Infante, I.; Snaith, H. J.; Manna, L., The Phosphine Oxide Route toward Lead Halide Perovskite Nanocrystals. Journal of the American Chemical Society 2018, 140 (44), 14878-14886.

67. Maes, J.; Balcaen, L.; Drijvers, E.; Zhao, Q.; De Roo, J.; Vantomme, A.; Vanhaecke, F.; Geiregat, P.; Hens, Z., Light Absorption Coefficient of CsPbBr3 Perovskite Nanocrystals. The Journal of Physical Chemistry Letters 2018, 9 (11), 3093-3097.

68. Wheeler, L. M.; Sanehira, E. M.; Marshall, A. R.; Schulz, P.; Suri, M.; Anderson, N. C.; Christians, J. A.; Nordlund, D.; Sokaras, D.; Kroll, T.; Harvey, S. P.; Berry, J. J.; Lin, L. Y.; Luther, J. 
M., Targeted Ligand-Exchange Chemistry on Cesium Lead Halide Perovskite Quantum Dots for High-Efficiency Photovoltaics. Journal of the American Chemical Society 2018, 140 (33), 1050410513.

69. Correa-Baena, J.-P.; Saliba, M.; Buonassisi, T.; Grätzel, M.; Abate, A.; Tress, W.; Hagfeldt, A., Promises and challenges of perovskite solar cells. Science 2017, 358 (6364), 739-744.

70. Vashishtha, P.; Halpert, J. E., Field-Driven Ion Migration and Color Instability in RedEmitting Mixed Halide Perovskite Nanocrystal Light-Emitting Diodes. Chemistry of Materials 2017, 29 (14), 5965-5973.

71. Slotcavage, D. J.; Karunadasa, H. I.; McGehee, M. D., Light-Induced Phase Segregation in Halide-Perovskite Absorbers. ACS Energy Letters 2016, 1 (6), 1199-1205.

72. Sasabe, H.; Kido, J., Recent Progress in Phosphorescent Organic Light-Emitting Devices. European Journal of Organic Chemistry 2013, 2013 (34), 7653-7663.

73. Zhao, B.; Bai, S.; Kim, V.; Lamboll, R.; Shivanna, R.; Auras, F.; Richter, J. M.; Yang, L.; Dai, L.; Alsari, M.; She, X.-J.; Liang, L.; Zhang, J.; Lilliu, S.; Gao, P.; Snaith, H. J.; Wang, J.; Greenham, N. C.; Friend, R. H.; Di, D., High-efficiency perovskite-polymer bulk heterostructure lightemitting diodes. Nature Photonics 2018, 12 (12), 783-789.

74. Burrows, P. E.; Bulovic, V.; Forrest, S. R.; Sapochak, L. S.; McCarty, D. M.; Thompson, M. E., Reliability and degradation of organic light emitting devices. Applied Physics Letters 1994, 65 (23), 2922-2924.

75. Friend, R. H.; Gymer, R. W.; Holmes, A. B.; Burroughes, J. H.; Marks, R. N.; Taliani, C.; Bradley, D. D. C.; Santos, D. A. D.; Brédas, J. L.; Lögdlund, M.; Salaneck, W. R., Electroluminescence in conjugated polymers. Nature 1999, 397, 121. 


\section{TOC:}

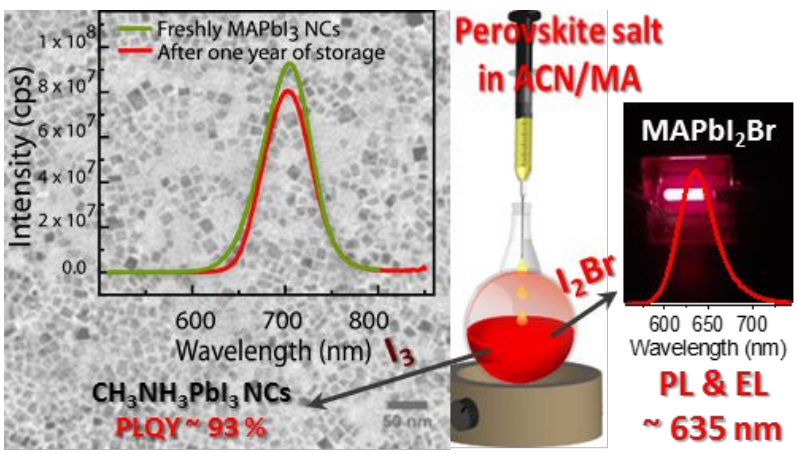

